\title{
A new aerosol flow reactor to study secondary organic aerosol
}

\author{
Kelly L. Pereira ${ }^{1}$, Grazia Rovelli ${ }^{2,3}$, Young C. Song ${ }^{2}$, Alfred W. Mayhew ${ }^{1}$, Jonathan P. Reid ${ }^{2}$, and \\ Jacqueline F. Hamilton ${ }^{1}$ \\ ${ }^{1}$ Wolfson Atmospheric Chemistry Laboratories, Department of Chemistry, University of York, York, YO10 5DD, UK \\ ${ }^{2}$ School of Chemistry, Cantock's Close, University of Bristol, Bristol, BS8 1TS, UK \\ ${ }^{3}$ Lawrence Berkeley National Laboratory, Chemical Sciences Division, Berkeley, CA 94720, USA
}

Correspondence: Jacqueline Hamilton (jacqui.hamilton@york.ac.uk)

Received: 18 January 2019 - Discussion started: 7 February 2019

Revised: 23 July 2019 - Accepted: 23 July 2019 - Published: 23 August 2019

\begin{abstract}
Gas-particle equilibrium partitioning is a fundamental concept used to describe the growth and loss of secondary organic aerosol (SOA). However, recent literature has suggested that gas-particle partitioning may be kinetically limited, preventing volatilization from the aerosol phase as a result of the physical state of the aerosol (e.g. glassy, viscous). Experimental measurements of diffusion constants within viscous aerosol are limited and do not represent the complex chemical composition observed in SOA (i.e. multicomponent mixtures). Motivated by the need to address fundamental questions regarding the effect of the physical state and chemical composition of a particle on gas-particle partitioning, we present the design and operation of a newly built $0.3 \mathrm{~m}^{3}$ continuous-flow reactor (CFR), which can be used as a tool to gain considerable insights into the composition and physical state of SOA. The CFR was used to generate SOA from the photo-oxidation of $\alpha$ pinene, limonene, $\beta$-caryophyllene and toluene under different experimental conditions (i.e. relative humidity, VOC and $\mathrm{VOC} / \mathrm{NO}_{x}$ ratios). Up to $10^{2} \mathrm{mg}$ of SOA mass was collected per experiment, allowing the use of highly accurate compositional- and single-particle analysis techniques, which are not usually accessible due to the large quantity of organic aerosol mass required for analysis. A suite of offline analytical techniques was used to determine the chemical composition and physical state of the generated SOA, including attenuated total reflectance infrared spectroscopy; carbon, hydrogen, nitrogen, and sulfur (CHNS) elemental analysis; ${ }^{1} \mathrm{H}$ and ${ }^{1} \mathrm{H}_{-}{ }^{13} \mathrm{C}$ nuclear magnetic resonance spectroscopy (NMR); ultra-performance liquid chromatography ultra-high-resolution mass spectrometry (UHRMS); highperformance liquid chromatography ion-trap mass spectrom-
\end{abstract}

etry (HPLC-ITMS); and an electrodynamic balance (EDB). The oxygen-to-carbon $(\mathrm{O} / \mathrm{C})$ and hydrogen-to-carbon $(\mathrm{H} / \mathrm{C})$ ratios of generated SOA samples (determined using a CHNS elemental analyser) displayed good agreement with literature values and were consistent with the characteristic Van Krevelen diagram trajectory, with an observed slope of -0.41 . The elemental composition of two SOA samples formed in separate replicate experiments displayed excellent reproducibility, with the $\mathrm{O} / \mathrm{C}$ and $\mathrm{H} / \mathrm{C}$ ratios of the SOA samples observed to be within error of the analytical instrumentation (instrument accuracy $\pm 0.15 \%$ to a reference standard). The ability to use a highly accurate CHNS elemental analyser to determine the elemental composition of the SOA samples allowed us to evaluate the accuracy of reported SOA elemental compositions using UHRMS (a commonly used technique). In all of the experiments investigated, the SOA O/C ratios obtained for each SOA sample using UHRMS were lower than the $\mathrm{O} / \mathrm{C}$ ratios obtained from the CHNS analyser (the more accurate and non-selective technique). The average difference in the $\Delta \mathrm{O} / \mathrm{C}$ ratios ranged from $19 \%$ to $45 \%$ depending on the SOA precursor and formation conditions. $\alpha$-pinene SOA standards were generated from the collected SOA mass using semi-preparative HPLC-ITMS coupled to an automated fraction collector, followed by ${ }^{1} \mathrm{H}$ NMR spectroscopy. Up to $35.8 \pm 1.6 \%$ (propagated error of the uncertainty in the slope of the calibrations graphs) of $\alpha$ pinene SOA was quantified using this method; a considerable improvement from most previous studies. Single aerosol droplets were generated from the collected SOA samples and trapped within an EDB at different temperatures and relative humidities to investigate the dynamic changes in their physiochemical properties. The volatilization of organic compo- 
nents from toluene and $\beta$-caryophyllene SOA particles at $0 \%$ relative humidity was found to be kinetically limited, owing to particle viscosity. The unconventional use of a newly built CFR, combined with comprehensive offline chemical characterization and single-particle measurements, offers a unique approach to further our understanding of the relationship between SOA formation conditions, chemical composition and physiochemical properties.

\section{Introduction}

Organic aerosol (OA) accounts for a substantial fraction of ambient particulate matter (Kroll and Seinfeld, 2008; Kanakidou et al., 2005, and references therein) and exhibits substantial chemical complexity. OA contains thousands of compounds of differing chemical functionalities, volatilities and masses (Goldstein and Galbally, 2007; Kanakidou et al., 2005; Seinfeld and Pankow, 2003). This chemical complexity poses a significant analytical challenge (Goldstein and Galbally, 2007; Nozière et al., 2015; Zhang et al., 2011). OA can be broadly characterized into two sources, primary organic aerosol, which is directly emitted into the atmosphere, and secondary organic aerosol (SOA), which is formed in the atmosphere from the oxidation of volatile organic compounds (VOCs). SOA formation mechanisms are poorly understood. It has been estimated that $10^{4}$ to $10^{5}$ VOCs are present in the atmosphere (Goldstein and Galbally, 2007). These VOCs can undergo numerous oxidation reactions, forming lower-volatility compounds, which can partition into particulate-phase-forming SOA. Once formed, the chemical composition of SOA can continue to evolve via absorptive partitioning (Donahue et al., 2006; Pankow, 1994a, b), reactive uptake of organic gases (Czoschke et al., 2003; Gaston et al., 2014; Iinuma et al., 2004; Jang et al., 2002; Kroll et al., 2005; Riva et al., 2017), heterogenous oxidation by gasphase radicals (George and Abbatt, 2010a, b; Kroll et al., 2015; Li et al., 2018) and in particle-phase reactions (Gao et al., 2004; Heaton et al., 2007; Kalberer et al., 2004; Tolocka et al., 2004).

The chemical and physical transformations of SOA are often studied using atmospheric simulation chambers or oxidative flow reactors (e.g. Bloss et al., 2005; Cocker et al., 2001; Friedman and Farmer, 2018; Glowacki et al., 2007; Hamilton et al., 2011; Hodshire et al., 2018; Liu and Zeng, 2018; Liu et al., 2018; Rohrer et al., 2005; Witkowski et al., 2018). These techniques allow SOA formation and ageing to be investigated under controlled conditions. The oxidation of a single VOC can be investigated, reducing atmospheric complexity and providing greater insights into SOA formation mechanisms. Atmospheric simulation chambers and oxidative flow reactors have several fundamental differences. Atmospheric simulation chambers range in size from $\sim 0.01$ to $250 \mathrm{~m}^{3}$ (Lambe et al., 2011). Reactants are typically intro- duced at the beginning of an experiment, and the chemistry is allowed to reach completion over several hours. VOC and oxidant mixing ratios are typically selected to simulate ambient conditions as closely as possible, whilst ensuring sufficient gaseous- and particulate-phase concentrations are obtained for measurement. In contrast, oxidative flow reactors are smaller in size, ranging from $\sim 0.001$ to $0.01 \mathrm{~m}^{3}$ (Lambe et al., 2011). Oxidative flow reactors are operated with the continuous introduction of reactants and high oxidant mixing ratios, simulating several days of chemistry within a few seconds or minutes (Bruns et al., 2015; Lambe et al., 2011). Atmospheric simulation chambers and oxidative flow reactors are the most advanced tools for reducing atmospheric complexity and elucidating the chemical and physical transformations of SOA that occur in the atmosphere. However, despite the use of these techniques, deducing the detailed chemical speciation of SOA is a formidable analytical challenge. There is no single analytical technique capable of providing the detailed chemical speciation of SOA with complete molecular characterization (Hallquist et al., 2009). As a result, multiple complementary analytical techniques are often used to investigate the chemical composition of SOA. However, many of these techniques are often hindered by the lack of authentic standards, further compounding the molecular identification and quantification of SOA components.

To accurately predict SOA mass loadings in the ambient atmosphere, the chemical and physical properties driving the dynamic mechanisms occurring during SOA formation and ageing must be understood. Conventionally, particles were assumed to exist as liquids, forming an instantaneous reversible equilibrium with the gas phase, as described by the gas-particle partitioning theorem (Donahue et al., 2006; Pankow, 1994a, b). However, studies have shown that the physical state of a particle can drastically reduce semi-volatile evaporation rates and in some cases, prevent evaporation (Grieshop et al., 2007; Perraud et al., 2012; Shiraiwa et al., 2013; Vaden et al., 2011). These kinetic limitations are driven by particle viscosity, which is influenced by temperature (Koop et al., 2011; Zobrist et al., 2008), relative humidity (Bateman et al., 2015; Mikhailov et al., 2009) and the chemical composition of the particle (Bateman et al., 2015; DeRieux et al., 2018; Grieshop et al., 2007; Huang et al., 2018; Kidd et al., 2014; Koop et al., 2011; Perraud et al., 2012; Reid et al., 2018; Roldin et al., 2014; Rothfuss and Petters, 2017b; Vaden et al., 2011). Recent studies have suggested that particle viscosity is influenced by certain chemical components within the SOA, such as oligomers (Huang et al., 2018) and nitrate-containing species (Perraud et al., 2012).

The aim of this work was to develop a methodology capable of furthering our understanding of the chemical and physical properties driving SOA transformation processes. Here, we describe the design and unconventional use of a newly built $0.3 \mathrm{~m}^{3}$ continuous-flow reactor (CFR). In contrast to the majority of atmospheric simulation chamber and 
reactor studies, we show how generating large quantities of SOA mass $\left(>10^{2} \mathrm{mg}\right.$ per experiment), which is usually avoided, can be used to gain greater insights into the complex physiochemical properties controlling gas-particle partitioning. VOCs and oxidants are continuously introduced into the reactor and sample air is extracted, operating under steadystate flow conditions (analogous to oxidative flow reactors), allowing a wide range of chemical scenarios to be investigated through the control of reactant mixing ratios and flow rates (i.e. residence time). In contrast to oxidative flow reactors, the developed CFR has a considerably larger volume $\left(0.3 \mathrm{~m}^{3}\right.$ vs. $\sim 0.001$ to $\left.0.01 \mathrm{~m}^{3}\right)$ and longer residence times (greater than $\sim 25 \mathrm{~min}$ vs. seconds to a few minutes), increasing the amount of SOA that can be formed in the reactor. Furthermore, studies have shown that the oxidation of some precursors with low condensational sinks may not achieve gas-particle equilibrium in reactors with residence times less than a few hundred seconds (Ahlberg et al., 2017; Anttila et al., 2016; Eluri et al., 2018; Palm et al., 2016). The longer residence times used in the CFR could potentially be used to overcome this, allowing the generated SOA more time to achieve equilibrium with the gas phase. High VOC and oxidant mixing ratios (i.e. parts-per-million by volume levels) are used in this study to generate large quantities of SOA mass. Consequently, the CFR has been designed to allow the reactor sampling bag to be rapidly replaced at minimal cost, significantly reducing reactor cleaning time in comparison to oxidative flow reactors that are constructed out of stainless steel or glass (e.g. Huang et al., 2017; Ihalainen et al., 2019). The use of CFRs within aerosol science is still very much in its infancy. CFRs have been used to study the gas-phase chemistry of isoprene (Liu et al., 2013; Zhang et al., 2018), SOA formed from the ozonolysis of $\alpha$-pinene (Shilling et al., 2008) and in animal toxicology to investigate the biological effect of exposure to SOA formed from the photooxidation of gasoline exhaust emissions (Papapostolou et al., 2011). In this study, the CFR was used to generate considerable quantities of SOA mass from the photo-oxidation of $\alpha$-pinene, limonene, $\beta$-caryophyllene and toluene under different experimental conditions. The SOA mass collected in each experiment was analysed using highly accurate compositional and single-particle analysis techniques, only possible because of the large amount of SOA mass that can be generated by the CFR. Preliminary compositional and singleparticle analysis data are presented, demonstrating the capabilities of the CFR. We show how the unconventional use of a newly built CFR, combined with comprehensive offline chemical characterization and single-particle measurements, offers a unique approach to further our understanding of the relationship between SOA formation conditions, chemical composition and physiochemical properties.

\section{Methods}

\subsection{Continuous-flow reactor design}

The CFR is located at the University of York, Wolfson Atmospheric Chemistry Laboratories. The CFR consists of a $0.3 \mathrm{~m}^{3}$ custom-made polyvinyl fluoride (PVF) sampling bag with the following dimensions: $1.5 \mathrm{~m}(\mathrm{l}) \times 1.0 \mathrm{~m}(\mathrm{w}) \times 0.2 \mathrm{~m}$ (h) (Adtech, Gloucester, UK). The sampling bag is enclosed within a rectangular aluminium housing and supported by a 0.75 in stainless steel hanging rail mounted inside the enclosure. The enclosure is constructed out of Bosch Rexroth rail (Bosch Rexroth, Cambridge, UK) with aluminium sheets covering each facia. A removable front facia panel provides access to the reactor. A schematic of the CFR is shown in Fig. 1 .

\subsubsection{Reactor}

The CFR has four inlets, three outlets and two septum seals. The two septum seals allow a UV pen-ray and coupled temperature and humidity sensor to be mounted inside the sampling bag. UV radiation is generated using a $\mathrm{Hg}$ pen-ray (UVP, Cambridge, UK), which emits at $254 \mathrm{~nm}$ (primary energy) and $185 \mathrm{~nm}$, forming ozone and hydroxyl radicals (in the presence of nitrous acid or water vapour) inside the reactor. The UV pen-ray can become hot to touch after several hours of operation. Approximately $60 \mathrm{~cm}$ of $0.0625 \mathrm{in}$. stainless steel tubing was wrapped around the UV pen ray in a cone shape, preventing the UV lamp from touching the sampling bag without blocking the light source. The reactor temperature and humidity are measured using a TE HTM2500LF sensor (Future Electronics, Surrey, UK) operated via a U3 LabJack (LabJack, Colorado, USA) and an in-house-built program in DAQFactory Express software. The sampling bag is covered in foil to maximize light intensity inside the reactor and minimize ozone formation inside the enclosure. Mass flow controllers are used to balance the in and out flows of the reactor, ensuring the reactor volume remains constant. Humidified air, nitric oxide, and one or two VOC precursors (i.e. mixed VOC precursor experiments) can be continuously introduced into the CFR via three separate inlets (see Fig. 1). The fourth inlet is used to rapidly fill the reactor with dry purified air prior to an experiment. Humidified air is generated by flowing dry purified air through a water bubbler. VOCs are introduced into the CFR by flowing a low flow rate $\left(<300 \mathrm{~mL} \mathrm{~min}^{-1}\right)$ of dry purified air through a temperature-controlled glass bulb, containing the VOC precursor in a liquid state and in excess. An additional flow of dry purified air (i.e. make-up flow) is used to rapidly transport the VOC vapour into the CFR via a heated stainless steel line, minimizing condensational losses of the VOC precursor. Gaseous- and particulate-phase measurements can be obtained via any of the three reactor outlets. 


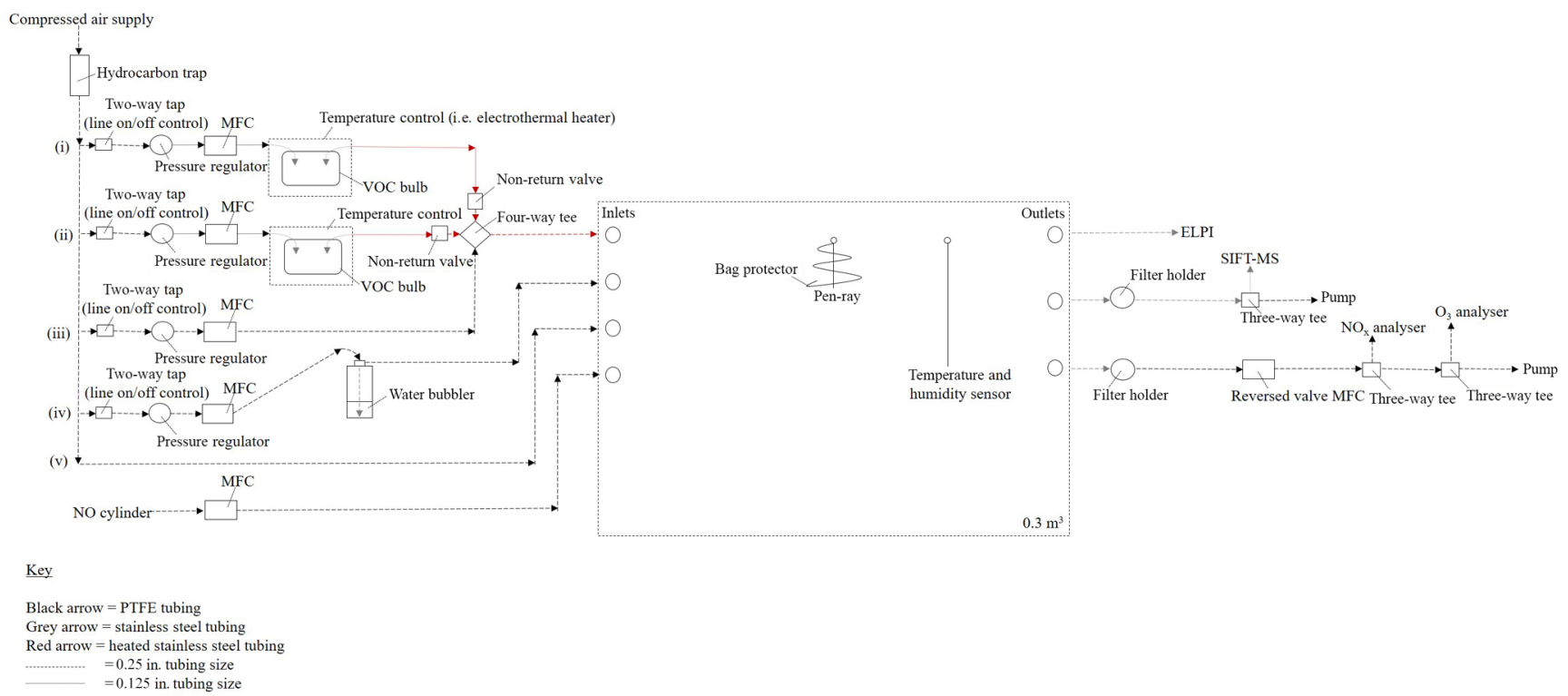

Figure 1. Detailed schematic of the continuous-flow reactor (CFR). Points (i) to (iv) refer to the text discussion of each introduction line; see Sect. 2.1.2. MFC is a mass flow controller, ELPI is a electrical low-pressure impactor and SIFT-MS is a selected ion flow tube mass spectrometer.

\subsubsection{Inlet system}

The reactor is supplied with dry hydrocarbon-scrubbed air from an oil-free compressed air generator (SPRST, Spiral air, Oxfordshire, UK) using an in-built water and in-line hydrocarbon trap (GateKeeper GPU gas purifier, Entegris, Billerica, USA). Dry hydrocarbon-scrubbed air is delivered to the inlet system through 0.25 in. perfluoroalkoxy (PFA) tubing at a pressure of $\sim 760 \mathrm{kPa}$ (output of compressed air generator). Five 0.25 in. PFA lines are connected to the main feed of dry hydrocarbon-scrubbed air. These lines are as follows: (i) VOC 1 (ii) VOC 2 (iii) make-up flow, (iv) humidity and (v) fast fill (see Fig. 1). The operation of each line is controlled by a $0.25 \mathrm{in}$. two-way tap. VOCs are introduced into the reactor through lines (i) and (ii).

A series of safety features have been installed in lines (i) and (ii) to ensure the upstream glassware is not subjected to high positive pressure. Immediately after the two-way tap, the tubing size of lines (i) and (ii) are reduced from 0.25 to $0.125 \mathrm{in}$. PFA. The pressure and flow rate in these lines are controlled to $<55 \mathrm{kPa}$ and $<300 \mathrm{~mL} \mathrm{~min}^{-1}$ using a 3 to 7 bar pressure regulator (product code 122-649, IMI Norgren, RS Components, Northants, UK) and a 0.005 to $1 \mathrm{~L} \mathrm{~min}^{-1}$ mass flow controller (Alicat, Premier Control Technologies, Norfolk, UK), respectively; at $\sim 70 \mathrm{kPa}$ the upstream glassware over-pressurizes and the gas-tight seals fail. VOC precursors are contained in $250 \mathrm{~mL}$ three-necked glass bulbs (271-1513, VWR International, Leicestershire, UK). Suba-seals (Sigma Aldrich, Dorset, UK) are used to cover each opening of the glass bulb, providing a gas-tight seal. Two pieces of $0.125 \mathrm{in}$. stainless steel tubing, filed at one end to create a sharp point, are inserted through the rubber gas-tight suba-seals on either end of the glass bulb, allowing dry hydrocarbon-scrubbed air to pass through the glassware. The suba-seal on the middle neck of the glass bulb acts as a pressure relief (in the event of over-pressuring) and is left unclamped with no attached tubing. Heated stainless steel lines (heated to $\sim 70^{\circ} \mathrm{C}$ ) are used from the outlet of the VOC bulb to the inlet of the CFR to minimize condensational losses of the VOC precursor. A non-return valve is installed directly after the VOC bulb on lines (i) and (ii); see Fig. 1. The non-return valves ensure the higher pressure and flow rate of the dry hydrocarbonscrubbed air in the make-up flow line does not enter lines (i) and (ii), which would result in the VOC glass bulbs overpressurizing. The VOC bulbs on lines (i) and (ii) can be temperature-controlled using a water or ethylene glycol bath (temperature range of -10 to $95{ }^{\circ} \mathrm{C}$, Grant, Cambridge, UK) or an electrothermal heater (temperature range of ambient to $450^{\circ} \mathrm{C}$, EM series, Cole-Parmer, Cambridge, UK), allowing greater control over the desired mixing ratio of the VOC precursors injected into the CRF (e.g. low-volatility VOCs can be heated to introduce higher mixing ratios into the reactor).

The make-up flow line consists of $0.25 \mathrm{in}$. PFA tubing with a pressure regulator, mass flow controller and 0.25 in. fourway tee, connecting the make-up flow with lines (i) and (ii) to the inlet of CFR (see Fig. 1). The pressure in this line is controlled to $\sim 140 \mathrm{kPa}$, which is a sufficient pressure to achieve the full flow range on a 0.1 to $20 \mathrm{~L} \mathrm{~min}^{-1}$ mass flow controller (Alicat, Premier Control Technologies, Norfolk, UK). The make-up flow has two functions: to rapidly transport the VOC precursor into the CFR and to balance the total outflows of the reactor. All other introduction lines except for the fast 
fill (not used during an experiment) require a set flow rate for a desired mixing ratio. The make-up flow effects overall dilution but does not require a set flow rate, allowing the flow to be increased or decreased as desired to counterbalance the outflows of the reactor. The remaining two lines connected to the main feed of dry hydrocarbon-scrubbed air are the humidity (iv) and fast-fill (v) lines. The humidity and fast-fill lines are connected to two separate reactor inlets (second and third inlet; see Fig. 1). The humidity line controls the amount of water vapour introduced into the reactor and is comprised of 0.25 in. PFA tubing with a pressure regulator, mass flow controller and a $1000 \mathrm{~mL}$ water bubbler (pyrex glass bottle with an in-house-built screw-top water bubbler attachment). The humidity line requires a slightly higher line pressure than the VOC lines due to the back-pressure created by flowing through the water bubbler. The pyrex glass bottle has thicker walls than the VOC glass bulbs, allowing a slightly higher line pressure to be used. The pressure in the humidity line is controlled to below $\sim 70 \mathrm{kPa}$; the lowest possible pressure to achieve the required flow rate. A maximum flow rate of $\sim 12 \mathrm{~L} \mathrm{~min}^{-1}$ was used in the humidity line and was controlled using a 0.1 to $20 \mathrm{~L} \mathrm{~min}^{-1}$ mass flow controller (Alicat, Premier Control Technologies, Norfolk, UK). Relative humidity in the reactor can be controlled by changing the ratio of humidity line flow rate/total reactor flow rate (linear relationship). The maximum relative humidity, which could be achieved in the reactor was $\sim 60 \%$. The fast-fill line is used to rapidly fill the reactor with dry hydrocarbon-scrubbed air. The fast-fill line pressure and flow rate are unregulated (i.e. output of compressed air generator), allowing the reactor to be rapidly filled when required. The pressure and flow rate of the fast-fill line can be loosely controlled using the 0.25 in. two-way tap. The final introduction line, which is not connected to the main feed of dry hydrocarbon-scrubbed air and subsequently not discussed above, is the nitric oxide line (see Fig. 1). A standard of nitric oxide (5 or $60 \mathrm{ppm}$ in $\mathrm{N}_{2}$, BOC, $\mathrm{UK}$ ) can be introduced into the CFR through the fourth reactor inlet using a 0.02 to $2 \mathrm{~L} \mathrm{~min}^{-1}$ mass flow controller (Alicat, Premier Control Technologies, Norfolk, UK). The nitric oxide cylinder is easily interchangeable, allowing other oxidants or scavengers to be introduced into the reactor if required.

\subsubsection{Outlet system}

Gaseous- and particulate-phase measurements can be obtained via any of the three reactor outlets. A variety of instruments can be coupled to the CFR and easily interchanged. The limiting factor of coupling multiple instruments to the CFR is the total reactor outflow. The higher the total reactor outflow, the more difficult it becomes to balance the reactor volume. At $30 \mathrm{~L} \mathrm{~min}^{-1}$, the reactor volume is replaced every 10 min. Mass flow controllers considerably reduce the difficulty in balancing the reactor volume when installed on the in and out flows of the reactor. However, over several hours of operation, the reactor volume can increase or decrease, due to the permeability of the PVF sampling bag and the error in the accuracy of numerous mass flow controllers. Quick changes can be made to reactor volume by shutting off all the in or out flows to the reactor for $\sim 1$ to $2 \mathrm{~min}$, decreasing or increasing the reactor volume, respectively.

Several instruments have been successfully coupled to the CFR. These include a selected ion flow tube mass spectrometer (SIFT-MS, SYFT Technologies, New Zealand) for the measurement of VOC mixing ratios and gaseous oxidation products; an electrical low-pressure impactor (ELPI, model ELPI+, Dekati, Finland) for SOA collection and real-time particle mass, number, and diameter measurements; and a $\mathrm{NO}_{x}$ (model 42i) and $\mathrm{O}_{3}$ (model 49i, Thermo Scientific, Warrington, $\mathrm{UK}$ ) analyser for the measurement of $\mathrm{NO}_{x}$ and $\mathrm{O}_{3}$ mixing ratios, respectively. The measurements from some of these instruments are discussed below.

\subsection{Experimental design and CFR operation}

The CFR was designed to generate larger quantities of SOA mass than achieved in most studies for offline chemical composition and single-particle analysis. Single-particle measurement techniques, such as an electrodynamic balance and aerosol optical tweezers, can provide information on the morphology, hygroscopicity and phase behaviour of SOA with unprecedented accuracy (see Krieger et al., 2012, for further information). These techniques allow the effect of environmental changes on the microphysical state of the SOA to be investigated in controlled laboratory conditions, allowing the fundamental processes governing gas-particle partitioning to be better understood. These techniques, however, require considerable quantities of SOA mass for ease of transfer to particle generators ( $>20 \mathrm{mg}$ of SOA per experiment). To achieve this quantity of SOA mass, high mixing ratios (i.e. parts-per-million by volume) of a VOC precursor and oxidants must be continuously introduced into a reactor over several hours of operation. The CFR is ideally suited for this application in comparison to larger and well-established atmospheric simulation chambers, due to the ability to quickly and easily clean the reactor lines and replace the sampling bag at minimal cost (GBP 400).

A series of experiments were performed in the CFR to investigate the composition and physical state of the SOA formed from the photo-oxidation of $\alpha$-pinene (purity $98 \%$, Sigma Aldrich, Dorset, UK), limonene (99\%) $\beta$ caryophyllene $(98.5 \%)$ and toluene $(99.9 \%)$ under different experimental conditions. These VOCs were selected as they include biogenic and anthropogenic emissions and wellstudied VOC systems, such as $\alpha$-pinene. The experimental descriptions and reactor operating conditions can be found in Table 1. The experiments were designed to systematically characterize the effect of individual and combined experimental conditions on the composition and physical state of the SOA formed. The experiments investigated the effect 
Table 1. Experimental descriptions, reactor operating conditions, VOC and oxidant mixing ratios, and amount of SOA mass collected. Exp. is an abbreviation for experiment.

\begin{tabular}{|c|c|c|c|c|c|c|c|c|c|c|}
\hline \multirow[t]{2}{*}{ Exp. } & \multirow{2}{*}{$\begin{array}{l}\text { Exp. } \\
\text { description }\end{array}$} & \multirow[t]{2}{*}{$\mathrm{RH}(\%)$} & \multirow[t]{2}{*}{$\mathrm{NO}_{x}$} & \multicolumn{2}{|c|}{ Actual conditions ${ }^{\mathrm{a}}$} & \multicolumn{3}{|c|}{ Exp. conditions } & \multicolumn{2}{|c|}{ SOA mass collected } \\
\hline & & & & $\begin{array}{l}\mathrm{RH} \\
(\%)\end{array}$ & $\begin{array}{r}\text { Temperature } \\
\left({ }^{\circ} \mathrm{C}\right)\end{array}$ & $\begin{array}{r}\text { VOC } \\
(\text { ppmv })^{b}\end{array}$ & $\mathrm{VOC}: \mathrm{NO}_{x}$ & $\begin{array}{r}\text { Exp. duration } \\
\text { (HH:MM) }\end{array}$ & $\begin{array}{r}\text { ELPI } \\
(\mathrm{mg})\end{array}$ & $\begin{array}{r}\text { Filter } \\
(\mathrm{mg})\end{array}$ \\
\hline 1 & $\begin{array}{l}\text { Chamber } \\
\text { background }\end{array}$ & & & $<$ LOD & $25.8 \pm 0.8$ & - & - & 04:34 & $-^{c}$ & 0.14 \\
\hline 2 & $\alpha$-pinene & 0 & - & $<$ LOD & $26.0 \pm 0.4$ & 26.3 & - & $05: 15$ & 46.03 & 31.08 \\
\hline 3 & $\alpha$-pinene & 20 & - & $21.3 \pm 0.5$ & $26.0 \pm 0.4$ & 26.3 & - & $04: 18$ & 82.02 & 61.69 \\
\hline 4 & $\alpha$-pinene & 40 & - & $38.3 \pm 1.4$ & $25.8 \pm 0.5$ & 26.2 & - & 05:00 & 103.73 & 73.53 \\
\hline 5 & $\alpha$-pinene & 55 & - & $51.0 \pm 1.5$ & $23.9 \pm 0.3$ & 26.2 & - & 05:17 & 130.21 & 88.67 \\
\hline 6 & $\begin{array}{l}\text { Chamber } \\
\text { background }\end{array}$ & & & $<$ LOD & $24.1 \pm 0.2$ & - & - & $02: 31$ & $-^{c}$ & 0.14 \\
\hline 7 & $\begin{array}{l}\alpha \text {-pinene, low } \\
\text { mixing ratio }\end{array}$ & 55 & Low & $58.7 \pm 0.6$ & $23.2 \pm 0.5$ & $2.1,6.2^{\mathrm{h}}$ & 13.0 & $04: 25$ & $-{ }^{c}$ & 5.54 \\
\hline 8 & $\alpha$-pinene & 55 & Low & $52.5 \pm 1.6$ & $24.1 \pm 0.4$ & 18.5 & 13.0 & 05:04 & 122.15 & 102.83 \\
\hline 9 & $\alpha$-pinene & 55 & Medium & $51.8 \pm 1.9$ & $25.4 \pm 0.4$ & 18.5 & 7.6 & 05:03 & 113.91 & 76.97 \\
\hline 10 & $\alpha$-pinene & 55 & High & $50.3 \pm 1.3$ & $26.2 \pm 0.4$ & 18.5 & 2.8 & $05: 20$ & 122.01 & 85.91 \\
\hline 11 & $\alpha$-pinene & 20 & Low & $17.6 \pm 0.9$ & $25.9 \pm 0.4$ & 18.5 & 13.0 & 05:08 & 88.56 & 65.17 \\
\hline 12 & $\alpha$-pinene & 20 & Medium & $18.0 \pm 0.6$ & $26.2 \pm 0.6$ & 18.5 & 7.6 & $06: 37$ & 120.91 & 87.83 \\
\hline 13 & $\alpha$-pinene & 20 & High & $19.2 \pm 1.0$ & $24.4 \pm 0.3$ & 18.5 & 2.8 & 04:08 & 75.95 & 58.53 \\
\hline 14 & $\begin{array}{l}\alpha \text {-pinene, low } \\
\text { mixing ratio }\end{array}$ & 55 & High & $48.3 \pm 1.4$ & $23.6 \pm 0.3$ & 2.1 & 2.7 & 02:19 & $-^{\mathrm{c}}$ & 6.93 \\
\hline 15 & $\begin{array}{l}\text { Chamber } \\
\text { background }\end{array}$ & & & $49.1 \pm 1.5$ & $22.9 \pm 0.2$ & - & - & $06: 37$ & $-{ }^{c}$ & 1.67 \\
\hline 16 & Limonene & 0 & - & $<$ LOD & $24.2 \pm 0.3$ & 18.4 & - & 05:07 & $-^{c}$ & 52.75 \\
\hline 17 & Limonene, repeat & 0 & - & $<$ LOD & $24.5 \pm 0.3$ & 23.1 & - & $06: 10$ & 47.59 & 84.21 \\
\hline 18 & Limonene & 20 & - & $16.9 \pm 0.9$ & $23.9 \pm 0.3$ & 23.1 & - & $05: 50$ & 74.69 & 69.05 \\
\hline 19 & Limonene & 55 & - & $49.8 \pm 1.4$ & $23.6 \pm 0.3$ & 23.1 & - & 06:00 & 82.78 & 73.34 \\
\hline 20 & Limonene & 20 & Low & $17.5 \pm 0.9$ & $24.5 \pm 0.3$ & 23.1 & 13.0 & $06: 29$ & 77.06 & 84.19 \\
\hline 21 & Limonene & 20 & High & $18.5 \pm 1.2$ & $24.4 \pm 0.2$ & 23.1 & 2.8 & $05: 20$ & 56.84 & 84.21 \\
\hline 22 & Limonene & 55 & Low & $49.9 \pm 1.3$ & $23.3 \pm 0.4$ & 23.1 & 13.0 & $06: 48$ & 97.50 & 77.41 \\
\hline 23 & Limonene, repeat & 55 & Low & $48.7 \pm 2.3$ & $23.1 \pm 0.4$ & 23.1 & 13.0 & $06: 47$ & 107.65 & 85.77 \\
\hline 24 & Limonene & 55 & High & $46.2 \pm 1.7$ & $23.2 \pm 0.5$ & 23.1 & 2.8 & $06: 47$ & 96.04 & 81.49 \\
\hline 25 & $\begin{array}{l}\text { Chamber } \\
\text { background }\end{array}$ & & & $50.2 \pm 1.0$ & $23.1 \pm 0.4$ & - & - & $03: 35$ & $-^{\mathrm{c}}$ & 0.11 \\
\hline 26 & $\beta$-caryophyllene & 0 & - & $<$ LOD & $24.3 \pm 0.4$ & 63.4 & - & 06:05 & 137.44 & 113.52 \\
\hline 27 & $\beta$-caryophyllene & 20 & - & $16.0 \pm 0.9$ & $24.0 \pm 0.3$ & 63.4 & - & $07: 28$ & 176.74 & 145.14 \\
\hline 28 & $\beta$-caryophyllene & 55 & - & $44.1 \pm 0.7$ & $23.2 \pm 0.4$ & 63.4 & - & $06: 24$ & 93.00 & 66.83 \\
\hline 29 & $\beta$-caryophyllene & 20 & Low & $15.7 \pm 0.7$ & $24.4 \pm 0.1$ & 45.6 & 13.0 & $06: 34$ & 141.64 & 99.73 \\
\hline 30 & $\beta$-caryophyllene & 20 & High & $17.4 \pm 2.1$ & $23.9 \pm 0.3$ & 45.6 & 2.8 & $07: 22$ & 59.22 & 42.83 \\
\hline 31 & $\beta$-caryophyllene & 55 & Low & $43.1 \pm 1.9$ & $23.5 \pm 0.3$ & 45.6 & 13.0 & $06: 47$ & 122.98 & 74.49 \\
\hline 32 & $\beta$-caryophyllene & 55 & High & $41.2 \pm 1.1$ & $23.1 \pm 0.2$ & 45.6 & 2.8 & $07: 26$ & 44.56 & 32.51 \\
\hline 33 & $\begin{array}{l}\text { Chamber } \\
\text { background }\end{array}$ & & & $41.7 \pm 2.2$ & $24.6 \pm 0.5$ & - & - & 06:59 & $-^{\mathrm{c}}$ & -g \\
\hline 34 & Toluene $^{\mathrm{d}, \mathrm{e}}$ & 55 & - & $41.7 \pm 2.0$ & $24.1 \pm 0.5$ & 23.1 & - & $05: 21$ & 21.06 & 20.98 \\
\hline 35 & Toluene $\mathrm{d}^{\mathrm{f} f \mathrm{f}}$ & 55 & - & $41.4 \pm 1.6$ & $24.0 \pm 0.5$ & 23.1 & - & 07:22 & 26.00 & 29.72 \\
\hline 36 & Toluene $\mathrm{e}^{\mathrm{d}, \mathrm{e}}$ & 55 & Low & $39.5 \pm 2.1$ & $23.8 \pm 0.5$ & 23.1 & 13.0 & $05: 45$ & 29.48 & 29.26 \\
\hline 37 & Toluene $\mathrm{d}^{\mathrm{d}, \mathrm{f}}$ & 55 & Low & $39.5 \pm 0.1$ & $24.3 \pm 0.4$ & 23.1 & 13.0 & 07:19 & 22.15 & 35.44 \\
\hline 38 & Toluene $\mathrm{e}^{\mathrm{e}}$ & 55 & High & $43.1 \pm 1.4$ & $24.3 \pm 0.1$ & 23.1 & 2.8 & 07:11 & 30.67 & 28.57 \\
\hline
\end{tabular}

of (i) relative humidity, (ii) $\mathrm{VOC} / \mathrm{NO}_{x}$ ratios, (iii) the combined effect of relative humidity and $\mathrm{VOC} / \mathrm{NO}_{x}$ ratios, and (iv) VOC mixing ratios ( $\alpha$-pinene experiments only). Reactants were continuously introduced into the CFR and the air sampled for real-time measurements and SOA collection. $\alpha$ pinene, limonene and toluene were introduced into the reactor at room temperature (temperature-controlled laboratory, $\sim 21^{\circ} \mathrm{C}$ ). $\beta$-caryophyllene was heated to $90^{\circ} \mathrm{C}$ in the VOC bulb using an electrothermal heater. The high mixing ratios (ppmv levels) used in the experiments shown in Table 1 were not measured using the SIFT-MS or $\mathrm{NO}_{x}$ analyser due to the risk of detector saturation. Instead, separate experiments were performed to measure $\alpha$-pinene and NO at lower mixing ratios, allowing an estimated and measured mixing ratio correction to be calculated. This correction ratio was then applied to all estimated VOC and NO mixing ratios, respectively. $\alpha$-pinene and NO mixing ratios were individually measured in two separate experiments. Both experi- 
ments were performed in the dark at $55 \%$ relative humidity, using the same total reactor flow rate (i.e. residence time) as the experiments shown in Table 1. No other oxidants or VOCs were introduced into reactor during these experiments. VOC mixing ratios were estimated from the pure component vapour pressures, calculated using an online property prediction tool (http://umansysprop.seaes.manchester.ac.uk/, last access: 6 February 19), taking into account reactor dilution and a factor correction for estimated vs. measured mixing ratios (based on $\alpha$-pinene). A small source of $\mathrm{NO}_{x}$ (primarily $\mathrm{NO}_{2}$, less than $\sim 20$ ppbv) was present in all experiments from the dry hydrocarbon-scrubbed air and also potentially from the photolysis of HONO present on the chamber walls (Carter et al., 1981, 1982; Sakamaki et al., 1983). A 5 ppm standard of $\mathrm{NO}$ in $\mathrm{N}_{2}$ (BOC, UK) was used in low $\alpha$-pinene mixing ratio experiments (exps. 7 and 14; see Table 1). In all other $\mathrm{NO}_{x}$ experiments, a $60 \mathrm{ppm}$ standard of $\mathrm{NO}$ in $\mathrm{N}_{2}$ (BOC, UK) was used. An insufficient amount of SOA mass was generated from the photo-oxidation of toluene using the described CFR setup and operation. Several changes were made to increase SOA formation. These include (i) changing the UV light source to a longer $\mathrm{Hg}$ penray (product code $=90-0004-01$, UVP, California, USA) and only investigating SOA formation at $55 \%$ relative humidity to increase $\mathrm{OH}$ radical formation and (ii) combining the SOA mass formed in two replicate experiments for each experimental condition investigated (see Table 1).

Each time a new VOC precursor was investigated, a new sampling bag was installed and the reactor lines and components were cleaned. The sampling bag was thoroughly cleaned before use by introducing humidified hydrocarbonscrubbed air ( $\sim 50 \%$ relative humidity) into the reactor under UV irradiation for $\sim 2 \mathrm{~d}$. Upon completion, the reactor was flushed with dry hydrocarbon-scrubbed air before performing a chamber background experiment (see Table 1). SOA mass and number concentrations in the chamber background experiments ranged from 9 to $268 \mu \mathrm{g} \mathrm{m}^{-3}$ and 1.1 to $4.4 \times 10^{6}$ particles $\mathrm{cm}^{-3}$, respectively. The SOA mass formed in the chamber background experiments represented $<3.2 \%$ of the SOA mass formed in the low $\alpha$-pinene mixing ratio experiments (exps. 7 and 14) and $<1.1 \%$ in all other experiments. The average number of particles formed in the chamber background experiments represented $11.0 \pm 12.5 \%$ (arithmetic mean \pm relative standard deviation, shown in percentage) of the average number of particles formed in the $\alpha$-pinene, limonene, $\beta$-caryophyllene and toluene experiments (excluding exps. 2 and 17; see Table 1). Experiments 2 and 17 formed fewer particles than the average number of particles observed in the chamber background experiments, the reason for which is unclear. At the start of each experiment, the reactor was filled to volume with dry hydrocarbonscrubbed air using the fast-fill line. The reactor was then flushed with humidified hydrocarbon-scrubbed air for approximately $1.5 \mathrm{~h}$ before setting the flow rates of the desired experimental relative humidity and (where applicable) nitric oxide mixing ratios. Water vapour and nitric oxide were continuously introduced into the reactor for $\sim 30 \mathrm{~min}$ before introducing the VOC precursor. After $\sim 25$ min of continuous VOC introduction, the UV light was switched on. Gaseous reactants were mixed in the CFR through flow and diffusion only. High flow rates $\left(\sim 12 \mathrm{~L} \mathrm{~min}^{-1}\right)$ were used in all of the experiments to accelerate mixing. Steady-state mixing ratios were achieved in the CFR after $\sim 50$ min of continuous introduction of nitric oxide and $\sim 25$ min for the VOC precursor (based on $\alpha$-pinene). The reactor was cleaned at the end of each experiment by introducing humidified hydrocarbonscrubbed air ( $\sim 50 \%$ relative humidity) into the reactor with the UV lamp on. The ozone generated from UV irradiation was left inside the reactor overnight and flushed with humidified hydrocarbon-scrubbed air the next morning.

Reactor temperature; relative humidity; and particle diameter, number, and mass measurements were recorded every second in real time from the start to the end of each experiment. Background particle diameter, number and mass measurements were obtained during the continuous infusion of the water vapour and (where applicable) nitric oxide. SOA was collected using both an ELPI and onto preconditioned $47 \mathrm{~mm}$ quartz fibre filters. The reactor was used as a tool to generate large quantities of SOA mass. Subsequently, no corrections have been made for gaseous- or particulatephase wall losses in this work. The ELPI was used in all the experiments shown in Table 1. The use of the SIFT-MS, $\mathrm{NO}_{x}$ and $\mathrm{O}_{3}$ analysers depended on their availability with other projects, although they were primarily used in the $\alpha$ pinene experiments. The calibration of these instruments is discussed in the Supplement. Quartz fibre filters were preconditioned in a furnace at $550^{\circ} \mathrm{C}$ for $5 \mathrm{~h}$ to remove any organic compounds before use. The ELPI collects particles with a size range of 0.006 to $10 \mu \mathrm{m}$ onto size-specific foillined impactor plates. The SOA collected from the ELPI in each experiment was transferred from all the foil-lined impactor plates (non-size-specific) into two clean glass vials and weighed. One vial was kept at the University of York for compositional analysis and the second vial shipped in dry ice $\left(-80^{\circ} \mathrm{C}\right)$ to the University of Bristol for single-particle measurements. The impactor foils were replaced and the impactor was cleaned with methanol and water prior to each experiment. All SOA samples were wrapped in foil to minimize photolysis degradation and stored in a freezer at $-20^{\circ} \mathrm{C}$ until analysis.

\subsection{SOA chemical characterization}

SOA samples were analysed using an extensive range of compositional and single-particle techniques including ultraperformance liquid chromatography ultra-high-resolution mass spectrometry (UPLC-UHRMS); ${ }^{1} \mathrm{H}$ and ${ }^{1} \mathrm{H}-{ }^{13} \mathrm{C}$ nuclear magnetic resonance spectroscopy (NMR); and attenuated total reflectance Fourier transform infrared spectroscopy (ATR-FTIR); as well as a carbon, hydrogen, nitro- 
gen, and sulfur (CHNS) elemental analyzer and an electrodynamic balance. In addition to the above techniques, highperformance liquid chromatography ion trap mass spectrometry with a semi-preparative column and an automated fraction collector was used to generate SOA standards to quantify individual components in $\alpha$-pinene SOA. The SOA mass collected from the ELPI was used for all of the above techniques, except for ATR-FTIR spectroscopy, where the SOA collected onto quartz fibre filters were used. The ELPI collects SOA onto foil-lined impactor plates, minimizing potential artefacts often associated with the collection of SOA onto porous substrates (e.g. filters), thereby eliminating timeconsuming extraction processes. The ATR attachment on the FTIR spectrometer, however, allows SOA filters to be directly analysed without requiring extraction. Subsequently, SOA filters were used for this technique. The sample preparation methods, instruments and their operating parameters are discussed below.

\subsubsection{Generating SOA standards}

Individual compounds in the SOA were isolated and collected using semi-preparative high-performance liquid chromatography ion-trap mass spectrometer (HPLC-ITMS) coupled to an automated fraction collector (FC 203B, Gilson, Dunstable, UK); an extension of the work performed by Finessi et al. (2014). An Agilent 1100 series HPLC (Berkshire, UK) and Bruker Daltonics HTC Plus ITMS (Bremen, Germany) were used. The semi-preparative column was a reverse-phase Ascentis $150 \mathrm{~cm} \times 10 \mathrm{~mm}$, with a $5 \mu \mathrm{m}$ particle size (Sigma Aldrich, Dorset, UK). The HPLC solvents consisted of water (LC-MS grade, optima, Fisher Scientific, UK) with $0.1 \%(v / v)$ formic acid (Sigma Aldrich, UK) (A) and methanol (B) (LC-MS grade, optima, Fisher Scientific, UK). Gradient elution was used, starting at $87 \%$ (A), decreasing to $27 \%$ (A) at $92 \mathrm{~min}$ and re-equilibrating to $87 \%$ (A) at $97 \mathrm{~min}$. A $5 \mathrm{~min}$ pre-run consisting of the starting mobilephase conditions was performed prior to each injection. The flow rate was set to $3.5 \mathrm{~mL} \mathrm{~min}^{-1}$ with an injection volume of $100 \mu \mathrm{L}$. The eluent post-column was split via a tee piece and two lengths of PEEK tubing to the ITMS and the automated fraction collector. The use of a narrower internal diameter PEEK tubing to the ITMS resulted in a split ratio of 1:8 ITMS:fraction collector. Electrospray ionization (ESI) was used with a nebulizer pressure of $483 \mathrm{kPa}$, dry gas flow rate of $12 \mathrm{~L} \mathrm{~min}^{-1}$ and a dry gas temperature of $365^{\circ} \mathrm{C}$. The ITMS was operated in negative and positive ionization mode with a scan range of $\mathrm{m} / z$ 50-600. Collisioninduced dissociation (CID) was used with a fragmentation amplitude of $2 \mathrm{~V}$. The data were analysed using ESI Compass 1.3 for HTC esquire version 4 . The fraction collector was preprogrammed with the retention times of the target compounds and collected into $10 \mathrm{~mL}$ glass vials. The collected fractions were evaporated to dryness using a solvent evaporator (model V10, Biotage, Hertford, UK) and re- suspended in $500 \mu \mathrm{L}$ deuterium oxide with $0.05 \%(w / w)$ of 3-(trimethylsilyl)propionic-2,2,3,3-d $\mathrm{d}_{4}$ acid (TSP) (Sigma Aldrich, UK). Finally, the collected fractions were transferred into $5 \mathrm{~mm}$ tubes (Wilmad, Sigma Aldrich, UK) for NMR analysis.

\subsubsection{NMR spectroscopy}

The collected fractions and SOA samples were analysed using one-dimensional ${ }^{1} \mathrm{H}$ and two-dimensional ${ }^{1} \mathrm{H}_{-}{ }^{13} \mathrm{C}$ heteronuclear single quantum correlation (HSQC) NMR spectroscopy. A $700 \mathrm{MHz}$ Bruker Daltonics Avance Neo NMR spectrometer equipped with a prodigy triple resonance cryoprobe was used. The operating temperature was set to $21^{\circ} \mathrm{C}$. The ${ }^{1} \mathrm{H}-\mathrm{NMR}$ spectra were acquired at $700 \mathrm{MHz}$, with a pulse sequence of $45^{\circ}$ and a relaxation delay of $4 \mathrm{~s}$. The number of scans was set to 640, resulting in a total runtime of $1 \mathrm{~h}$ and $8 \mathrm{~min}$. The ${ }^{1} \mathrm{H}^{-13} \mathrm{C}$-NMR HSQC Bruker Daltonics pulse program used was hsqcetgpsi2 with a time domain data size of 256 and 1024 for channels F1 and F2, respectively. The number of scans was set to 20 , resulting in a total runtime of $1 \mathrm{~h}$ and $40 \mathrm{~min}$. The ${ }^{1} \mathrm{H}$ NMR spectra were analysed using TopSpin version 3.5 (Bruker Daltonics, Bremen, Germany). All spectra were baseline corrected and a spectral line broadening of $0.3 \mathrm{~Hz}$ was used. The concentration of the collected fractions was determined using the peak integrals of the internal standard (i.e. TSP) and the methyl group observed in the collected fractions from ${ }^{1} \mathrm{H}-\mathrm{NMR}$ spectroscopy (see Finessi et al., 2014, and Bharti and Roy, 2012, for further information). The compound structure of the collected fractions was determined using a combination of techniques, including ${ }^{1} \mathrm{H}$ and ${ }^{1} \mathrm{H}_{-}{ }^{13} \mathrm{C}-\mathrm{HSQC}$ NMR spectroscopy and the fragmentation patterns obtained from CID using the HPLC-ITMS and higher-energy collisional dissociation (HCD) using the UPLC-UHRMS. The ${ }^{1} \mathrm{H}_{-}{ }^{13} \mathrm{C}$ HSQC spectra were analysed using Spectrus Processor (ACD labs, Bracknell, UK), which contains an in-built carbon-hydrogen coupling prediction tool. This prediction tool provides estimated chemical shifts of carbon-hydrogen bonds in drawn chemical structures. Chemical structures of known and structurally similar photo-oxidation products of toluene and $\beta$ caryophyllene were drawn in the Spectrus Processor software to aid in the interpretation of the spectra discussed in Sect. 3.2.2.

\subsubsection{Ultra-high-resolution mass spectrometry}

A proportion of the ELPI SOA mass collected from each experiment was transferred into a clean vial and dissolved in 50:50 methanol: water (optima, LC-MS grade, Fisher Scientific, UK). The $\alpha$-pinene standards and SOA samples were analysed using ultra-performance liquid chromatography with a UV/Vis detector (Dionex 3000, Thermo Scientific, Warrington, UK) coupled to an ultra-high-resolution mass spectrometer (QExactive Orbitrap, Thermo Scientific, 
Warrington, UK). An Accucore reverse-phase $\mathrm{C}_{18}$ column $100 \mathrm{~mm} \times 2.1 \mathrm{~mm}$ with a $2.6 \mu \mathrm{m}$ particle size was used for compound separation (Thermo Scientific, Warrington, UK). The mobile phase consisted of water with $0.1 \%(v / v)$ formic acid (A) and methanol (B) (optima LC-MS grade, Fisher Scientific, UK). Gradient elution was used, holding at $10 \%$ (A) for $1 \mathrm{~min}$ after injection, decreasing to $90 \%$ (A) at $26 \mathrm{~min}$, followed by re-equilibration to $10 \%$ (A) at $28 \mathrm{~min}$. A $2 \mathrm{~min}$ pre-run of the starting mobile-phase conditions was performed prior to each injection. The flow rate was set to $0.3 \mathrm{~mL} \mathrm{~min}^{-1}$, with a $2 \mu \mathrm{L}$ injection volume. The column temperature was controlled at $40^{\circ} \mathrm{C}$ and the samples were kept at $4{ }^{\circ} \mathrm{C}$ in the autosampler tray during analysis. The UV/Vis wavelength ranged from 190 to $800 \mathrm{~nm}$ with a data collection rate of $5 \mathrm{~Hz} \mathrm{~s}^{-1}$. Heated electrospray ionization (HESI) was used, with the following parameters: sheath gas flow rate of 70 (a.u.), aux gas flow rate of 3 (a.u.), capillary temperature of $320^{\circ} \mathrm{C}$ and an aux gas heater temperature of $320^{\circ} \mathrm{C}$. Spectra were acquired in negative and positive ionization mode with a scan range of $\mathrm{m} / \mathrm{z} 85$ to 750 . Higher-energy collisional dissociation (HCD) was used with a stepped fragmentation amplitude of 65 and 115 (normalized collision energy, NCE). The number of most abundant precursors selected for fragmentation per scan was set to 10 , with a $3 \mathrm{~s}$ dynamic exclusion and an apex trigger of 2 to $4 \mathrm{~s}$. Two authentic standards, cis-pinonic acid (purity $98 \%$, Sigma Aldrich, UK) and pinic acid (Santa Cruz Biotechnology, Netherlands), were used for $\alpha$-pinene SOA quantification. Chromatographic integration was performed using the software package Freestyle version 1.1 (Thermo Scientific, Warrington, UK). SOA samples were also analysed using the software package Compound Discoverer version 2.1 (Thermo Scientific, Warrington, UK), which was used to extract all chromatographic peaks with a signal-to-noise ratio greater than 3 from the spectra, identify the molecular formulae and perform a mass spectral library search using $\mathrm{m} / \mathrm{z}$ Cloud (https://www.mzcloud.org/, last access: 17 April 2018). Molecular formulae were calculated using the following restrictions: unlimited $\mathrm{C}, \mathrm{H}$ and $\mathrm{O}$ atoms were allowed with a maximum of five $\mathrm{N}$ atoms. In positive ionization mode, up to three $\mathrm{Na}$ and two $\mathrm{K}$ atoms were also allowed. Compounds with assigned molecular formulae outside of the following tolerances were excluded from the data set: oxygen-to-carbon ratio $(\mathrm{O} / \mathrm{C}) 0.05$ to 2 , hydrogento-carbon $(\mathrm{H} / \mathrm{C}$ ) ratio 0.7 to 2 (following the lower limits provided in Bateman et al., 2009), double bond equivalent (DBE) $<20$, molecular formulae accuracy $<3 \mathrm{ppm}$. Chromatographic peaks identified in the solvent or procedural blanks and the SOA samples were removed from the data set.

\subsubsection{ATR-FTIR spectroscopy}

SOA filter samples were analysed using Fourier transform infrared spectroscopy with a diamond-attenuated total re- flectance attachment (ATR-FTIR, ALPHA, Bruker Daltonics, Bremen, Germany). The scan range was set to 500 $4000 \mathrm{~cm}^{-1}$, with a spectral resolution of $4 \mathrm{~cm}^{-1}$. Spectra were acquired in absorbance with 40 scans per sample. A preconditioned blank filter was used as the background measurement correcting for any instrument drift during analysis (cf. Coury and Dillner, 2009). The background measurement was subtracted from the sample spectra. The crystal was cleaned with isopropanol prior to the analysis of each sample or background measurement. Three replicate measurements were obtained for each sample. Spectral analysis was performed using essential FTIR software (eFTIR, Madison, USA). Spectra were ATR-corrected using the automated function in eFTIR software package. The use of quartz fibre filters will result in two silicon dioxide absorption peaks at wavenumbers $\sim 1060$ and $804 \mathrm{~cm}^{-1}$. This region of spectra provided no additional compositional information when comparing the SOA obtained from the ELPI with the quartz fibre filter.

\subsubsection{CHNS elemental analysis}

The elemental composition of the SOA was determined using a carbon, hydrogen, nitrogen and sulfur (CHNS) elemental analyser (model CE-440, Exeter Analytical, Coventry, UK). SOA samples were weighed using a Sartorius SE2 analytical balance (Surrey, UK). The reported elemental composition consists of an average of two replicate measurements. The remaining proportion of the SOA mass that did not contain elements $\mathrm{C}, \mathrm{H}, \mathrm{N}$ or $\mathrm{S}$ has been attributed to $\mathrm{O}$.

\subsection{Single-particle analysis}

The confinement of single aerosol particles within optical, electrodynamic or acoustic traps, or on surfaces, allows detailed information on their chemical-physical properties and dynamics to be obtained in isolated and controlled laboratory conditions (Krieger et al., 2012). In this work, a concentric cylindrical electrodynamic balance (CC-EDB) was used to trap single SOA particles to obtain information on some of the evolving chemical-physical properties of single SOA particles, such as their volatility distribution, possible kinetic limitations on evaporative loss of volatile species, hygroscopic and optical properties, phase state, and occurrence of liquid-phase separation (Marsh et al., 2017). All this information, coupled with the thorough chemical characterization of the SOA samples described in the previous sections, represents a unique set of experimental observations that will allow a deeper understanding of the complexity behind the dynamics of SOA in the atmosphere.

To prepare the SOA samples from CFR experiments for analysis in a CC-EDB, the collected aerosol mass was extracted in a $50: 50$ water: ethanol mixture (SOA mass fraction of $\sim 0.02$ ). The extracts were stored at $-20^{\circ} \mathrm{C}$ in a freezer to minimize any evaporative losses. Single charged 
droplets were generated from the extract solutions using a micro dispenser (Microfab MJ-ABP-01, initial radius of $\sim 18-25 \mu \mathrm{m}$ ) and trapped within $\sim 100 \mathrm{~ms}$ from generation in the EDB electrodynamic field, up to timescales of days. Once trapped, an individual droplet sits within a nitrogen flow with controlled temperature and $\mathrm{RH}$ (gas flow velocity of $3 \mathrm{~cm} \mathrm{~s}^{-1}$, RH range of $0 \%-95 \%, T$ range of $257-313 \mathrm{~K}$ ). Single particles are also illuminated with light from a $532 \mathrm{~nm}$ wavelength laser and the scattered light, centred on an angle of $45^{\circ}$, is collected by means of a CCD camera. The angularly resolved scattering pattern can be used to estimate the evolving size of the droplet, by applying the geometric optics approximation (Glantschnig and Chen, 1981), or on both size and refractive index, by fitting the generated phase functions with Mie theory simulations (using procedure reported by Cotterell et al., 2015). The experimental setup and operation in this work have been extensively described in previous publications (Davies et al., 2012; Rovelli et al., 2016) and we refer to these for a more detailed description.

\section{Results}

\subsection{Preliminary SOA characterization}

In total, 38 experiments were performed in the CFR to generate SOA mass from the photo-oxidation of $\alpha$-pinene, limonene, $\beta$-caryophyllene and toluene for offline chemical composition and single-particle analysis. The experiments investigated the effect of (i) relative humidity, (ii) $\mathrm{VOC} / \mathrm{NO}_{x}$ ratios, (iii) the combined effect of relative humidity and VOC $/ \mathrm{NO}_{x}$ ratios, and (iv) VOC mixing ratios ( $\alpha$-pinene experiments only). The reactor conditions, reactant mixing ratios and the amount of SOA mass collected in each experiment is shown in Table 1. The reactor temperature remained relatively stable throughout all experiments, with an average of $24.1 \pm 1.0^{\circ} \mathrm{C}$. The average experimental duration was $5 \mathrm{~h}$ and $45 \mathrm{~min}$. The total amount of SOA mass collected in each experiment (i.e. sum of ELPI + filter) ranged from 42 to $322 \mathrm{mg}$, excluding the low $\alpha$-pinene mixing ratio (range $=5$ to $7 \mathrm{mg}$ ) and chamber background experiments (see Table 1). The reactor conditions and SOA formation in a typical CFR experiment are shown in Fig. 2. The reactor temperature increased by $1.4^{\circ} \mathrm{C}$ after turning the UV lamp on, stabilizing $\sim 50 \mathrm{~min}$ into the experiment shown in Fig. 2 . Background SOA mass and number concentrations were $8.1 \pm 2.0 \mu \mathrm{g} \mathrm{m}^{-3}$ and $6.9 \times 10^{3} \pm 1.7 \times 10^{3}$ particles $\mathrm{cm}^{-3}$, respectively. In contrast to atmospheric simulation chambers, where reactants are typically introduced at the beginning of an experiment, the continuous introduction of reactants into the CFR resulted in a stable formation of SOA mass and number concentrations (Fig. 2). Particle number concentrations increased significantly upon UV radiation. The maximum number of particles observed in the typical CFR experiment shown in Fig. 2 was $1.7 \times 10^{8}$ particles $\mathrm{cm}^{-3}$, (a)
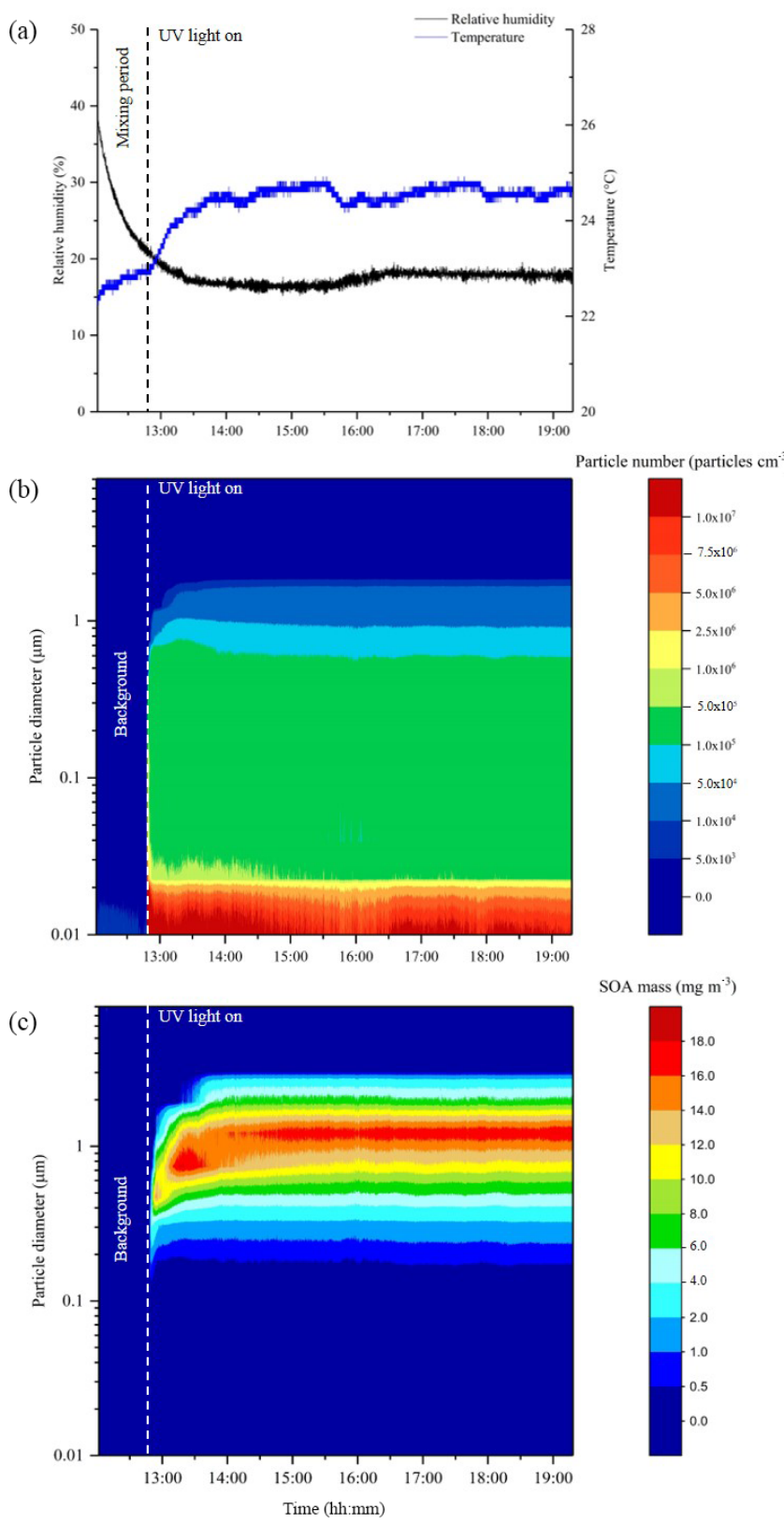

Figure 2. Data from a typical CFR experiment, displaying reactor relative humidity and temperature (a), particle diameter and number (b), and particle diameter and mass (c). Measurements are from the photo-oxidation of limonene at $20 \%$ relative humidity with a VOC/NO $\mathrm{Na}_{x}$ ratio of 13 (exp. 20, Table 1).

which plateaued $\sim 10 \mathrm{~min}$ into the experiment at $1.3 \pm 0.24 \times$ $10^{7}$ particles $\mathrm{cm}^{-3}$. Following particle nucleation, SOA mass gradually increased, plateauing $\sim 50 \mathrm{~min}$ into the experiment at $43.6 \pm 1.0 \mathrm{mg} \mathrm{m}^{-3}$. The total amount of SOA mass collected in this experiment was $161 \mathrm{mg}$ over $6 \mathrm{~h}$ and $29 \mathrm{~min}$.

Visual and physical differences were observed in the SOA samples generated from the experiments shown in Table 1. The SOA mass formed from the photo-oxidation of $\beta$ - 


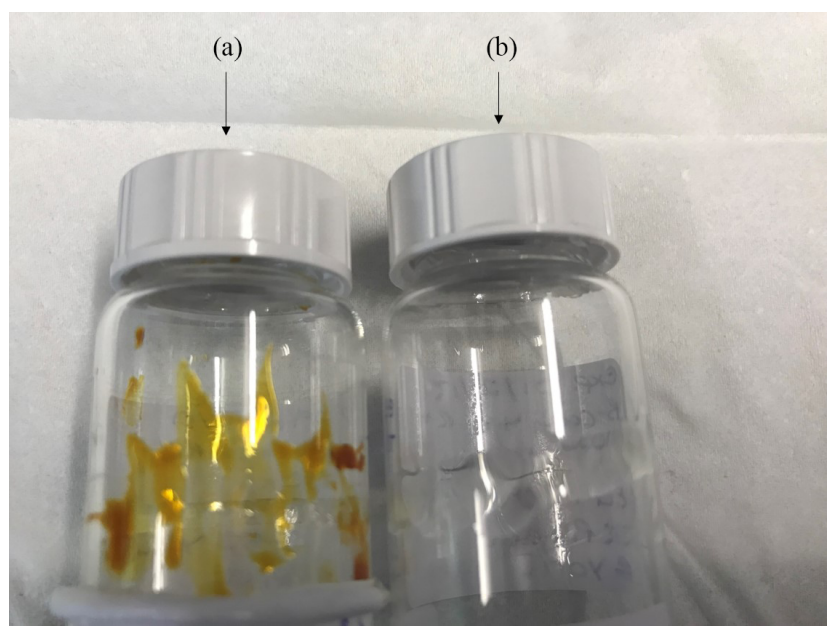

Figure 3. Visual differences observed in the light-absorbing properties of toluene (a) and $\beta$-caryophyllene SOA (b) formed under replicate experimental conditions $(55 \%$ relative humidity with a VOC $/ \mathrm{NO}_{x}$ ratio of 13 , exps. 36 and 31, respectively (see Table 1).

caryophyllene and toluene under replicate experimental conditions (exps. 31 and 36, respectively) are shown in Fig. 3. Both experiments investigated SOA formation at $55 \%$ relative humidity with a $\mathrm{VOC} / \mathrm{NO}_{x}$ of 13 . From Fig. 3, it can be observed that the SOA samples display considerable visual differences. The SOA formed from the photooxidation of toluene is yellow-brown in colour, displaying strong light-absorbing properties in the visible spectrum. Conversely, the SOA formed from the photo-oxidation of $\beta$ caryophyllene is translucent, suggesting the SOA has negligible visible light-absorbing properties. The SOA mass with the strongest light-absorbing properties was formed under the lowest $\mathrm{VOC} / \mathrm{NO}_{x}$ ratios (highest $\mathrm{NO}_{x}$ mixing ratios), as observed in Fig. S1 in the Supplement and previous studies (Liu et al., 2016; Nakayama et al., 2010; Xie et al., 2017). The viscosity of the SOA samples also appeared to decrease with increasing relative humidity, an observation which is commonly reported in the literature (Bateman et al., 2015; Kidd et al., 2014; Koop et al., 2011; Mikhailov et al., 2009; Montgomery et al., 2015; Reid et al., 2018; Rothfuss and Petters, 2017a).

The FTIR spectra of the SOA formed from the photooxidation of $\alpha$-pinene, limonene, $\beta$-caryophyllene and toluene under replicate experimental conditions $(55 \%$ relative humidity with a $\mathrm{VOC} / \mathrm{NO}_{x}$ ratio of 3 ) are shown in Fig. 4. The absorbance frequencies of five chemical functionalities are highlighted in Fig. 4. These absorbance frequencies correspond to a hydroxyl (wavenumber 3100$\left.3600 \mathrm{~cm}^{-1}\right)$, aliphatic $\left(3000-2850 \mathrm{~cm}^{-1}\right)$, carbonyl (1750$\left.1680 \mathrm{~cm}^{-1}\right)$, nitrate $\left(\sim 1630 \mathrm{~cm}^{-1}\right)$ and an aromatic nitro group $\left(1535-1525 \mathrm{~cm}^{-1}\right.$ ) (see Cao et al., 2018, and references therein for wavenumber assignments). Several expected compositional differences were observed in the SOA samples. For example, $\beta$-caryophyllene SOA displayed the highest intensity of aliphatic functionality. $\beta$-caryophyllene has a molecular formula of $\mathrm{C}_{15} \mathrm{H}_{22}$ with a molecular weight of $204.36 \mathrm{~g} \mathrm{~mol}^{-1}$. $\alpha$-pinene $\left(\mathrm{C}_{10} \mathrm{H}_{16}\right)$, limonene $\left(\mathrm{C}_{10} \mathrm{H}_{16}\right)$ and toluene $\left(\mathrm{C}_{7} \mathrm{H}_{8}\right)$ all contain considerably fewer carbon and hydrogen atoms in their molecular formula. $\beta$ caryophyllene was thus the largest chemical structure investigated, accounting for the high-intensity aliphatic peak observed. Organic nitrate functionalities are formed in the presence of $\mathrm{NO}$ via the reaction $\mathrm{RO}_{2}+\mathrm{NO}$ (e.g. Kroll and Seinfeld, 2008). All the SOA samples shown in Fig. 4 were formed in presence of $\mathrm{NO}$ and contained nitrate functionalities. Moreover, the aromatic nitro functionality (formed in the presence of $\mathrm{NO}_{2}$ ) was only observed in the SOA generated from the photo-oxidation of toluene (an aromatic VOC).

\subsection{CFR capabilities}

Typical chamber experiments generate $<100 \mu \mathrm{g}$ of SOA mass per experiment (e.g. Nozière et al., 2015; Xie et al., 2017). The design and operation of the CFR allowed considerable quantities of SOA mass to be collected per experiment $\left(>10^{2} \mathrm{mg}\right)$. This considerable quantity of SOA mass allowed us to use compositional and single-particle techniques which could not have otherwise been used (techniques requiring $\sim 1$ to $50 \mathrm{mg}$ of SOA mass per analysis). Here, we take advantage of the opportunity provided by the CFR to compare some of the critical chemical and physical properties of SOA from different precursors, which was previously not possible. The following discussion is limited to the characterization and capabilities of the CFR. A separate publication will discuss the composition and chemical-physical properties findings of this work.

\subsubsection{Elemental composition}

The elemental composition of the SOA samples was determined using a CHNS elemental analyser. CHNS analysis offers high accuracy and precision but is rarely used within aerosol science due to the large amount of organic aerosol mass required per analysis $(1-5 \mathrm{mg})$. Elemental composition is usually determined using aerosol mass spectrometry (AMS) or electrospray ionization ultra-high-resolution mass spectrometry (Liu et al., 2018; Tasoglou and Pandis, 2015; Tuet et al., 2017; Zhao et al., 2015; Kroll et al., 2011, and references therein). Whilst both mass-spectrometric techniques are invaluable within aerosol science, both methods suffer from inaccuracies, either through the use of a selective ionization source (i.e. ESI) or assumptive corrections in AMS data processing (Canagaratna et al., 2015). The $\mathrm{H} / \mathrm{C}$ and $\mathrm{O} / \mathrm{C}$ ratios and the average carbon oxidation state $\left(\overline{\mathrm{OS}}_{c}=\right.$ $2 \times \mathrm{O} / \mathrm{C}-\mathrm{H} / \mathrm{C}$; see Kroll et al., 2011, for further information) were calculated from the CHNS data for each SOA sample. The $\mathrm{O} / \mathrm{C}$ and $\mathrm{H} / \mathrm{C}$ ratios ranged from 0.41 to 0.45 and 1.57 to 1.67 for $\alpha$-pinene SOA, 0.45 to 0.49 and 1.59 


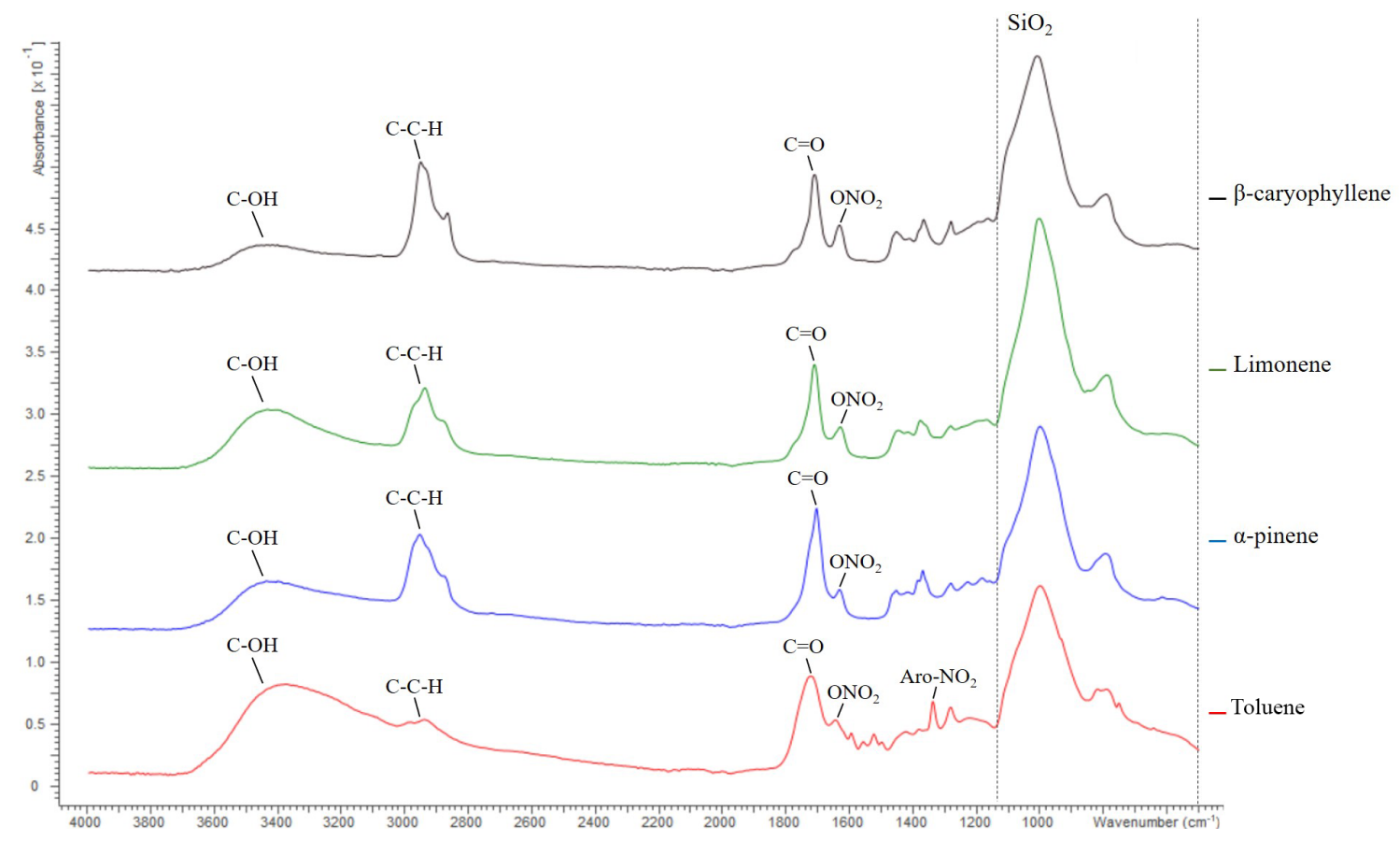

Figure 4. ATR-FTIR spectroscopy spectra of $\beta$-caryophyllene, limonene, $\alpha$-pinene and toluene SOA displaying absorption frequencies of organic functional groups. The quartz filter (i.e. $\mathrm{SiO}_{2}$ ) absorption region is highlighted by a dashed line; see the text for further information. Data from exps. 10, 24, 32 and 38; see Table 1. SOA was formed at $55 \%$ relative humidity with a VOC/NO $\mathrm{Natio}$ of for all SOA samples shown above.

to 1.71 for limonene SOA, 0.22 to 0.36 and 1.60 to 1.67 for $\beta$-caryophyllene SOA and 0.78 to 0.84 and 1.35 to 1.45 for toluene SOA, respectively. The elemental composition of two SOA samples formed under replicate conditions (exps. 22 and 23; see Table 1) displayed excellent agreement, with the $\mathrm{O} / \mathrm{C}$ and $\mathrm{H} / \mathrm{C}$ ratios observed to be within error of the analytical instrumentation (instrument accuracy $\pm 0.15 \%$ for a reference standard, as quoted by the manufacturer EAI, 2018).

A Van Krevelen diagram showing the $\mathrm{H} / \mathrm{C}$ vs. $\mathrm{O} / \mathrm{C}$ ratios of the SOA samples generated in this study, with a comparison to literature values, is shown in Fig. 5. The high VOC mixing ratios used in this study will result in highervolatility oxidation products partitioning into the particulate phase than observed at lower (ambient) mixing ratios, likely affecting the observed chemical composition (Donahue et al., 2006; Pankow, 1994a, b). However, from Fig. 5 it can be observed that the $\mathrm{H} / \mathrm{C}$ and $\mathrm{O} / \mathrm{C}$ ratios of the SOA samples display good agreement with the literature values, suggesting that for the experimental conditions investigated, the bulk elemental composition is largely unaffected by the use of high VOC mixing ratios. It is worth noting that a further study, not included in Fig. 5 due to the large number of data points, reported $\mathrm{H} / \mathrm{C}$ ratios ranging between $\sim 1.4$ to 1.7 for $\alpha$-pinene SOA, which is consistent with the results shown in this work (Zhao et al., 2015). Laboratory and ambient OA has been found to follow a general trajectory in the Van Krevelen diagram (Chen et al., 2015; Heald et al., 2010; Ng et al., 2011a).
An approximate -1 slope was first proposed by Heald et al. (2010) and was later re-evaluated to an approximate slope of -0.5 (Chen et al., 2015; Ng et al., 2011b). The SOA samples generated in this study were consistent with the characteristic Van Krevelen diagram trajectory, with a slope of -0.41 observed for all SOA precursors investigated.

The ability to use a highly accurate CHNS elemental analyser to determine the elemental composition of the SOA samples, allowed us to evaluate the accuracy of SOA elemental compositions obtained using UHRMS. The $\mathrm{O} / \mathrm{C}$ and $\mathrm{H} / \mathrm{C}$ ratios were calculated from the UHRMS using the assigned molecular formulae in each SOA sample. The total number of compounds (sum of positive and negative ionization mode) identified in each SOA sample ranged from 100 to 910; see Table S1 in the Supplement. Peak area weighted $\mathrm{O} / \mathrm{C}$ and $\mathrm{H} / \mathrm{C}$ ratios were calculated using the equation shown in Bateman et al. (2009), substituting peak intensity for peak area. In all of the experiments performed, the O/C ratios obtained for each SOA sample using UHRMS were lower than the $\mathrm{O} / \mathrm{C}$ ratios obtained from the CHNS analyser (the non-selective and more accurate technique); see Fig. S2. The SOA $\Delta \mathrm{O} / \mathrm{C}$ ratios varied for each SOA precursor, with an average $\Delta \mathrm{O} / \mathrm{C}$ of $0.08 \pm 0.01,0.13 \pm 0.01,0.06 \pm 0.03$ and $0.36 \pm 0.08$ for $\alpha$-pinene, limonene, $\beta$-caryophyllene and toluene SOA, respectively. For toluene SOA, this means that the average $\mathrm{O} / \mathrm{C}$ ratio would have been under reported by $45 \%$ if obtained from UHRMS (using the data processing 


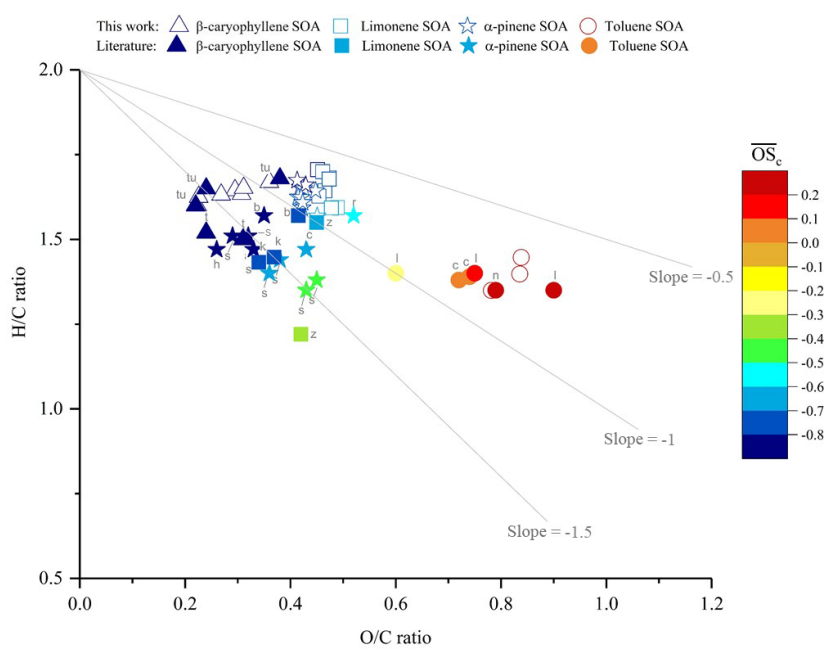

Figure 5. Comparison of the elemental hydrogen-to-carbon ratio (H/C, $y$ axis), oxygen-to-carbon ratio $(\mathrm{O} / \mathrm{C}, x$ axis) and average carbon oxidation state $\left(\overline{O S}_{c}\right.$, colour scale) of the SOA formed from the photo-oxidation of $\beta$-caryophyllene, limonene, $\alpha$-pinene and toluene in this study (unfilled shapes) vs. literature values (colourfilled shapes). Letters correspond to the references where the literature values were obtained: b, Bateman et al. (2009); n, Nakao et al. (2013); r, Reinhardt et al. (2007); tu, Tuet et al. (2017); t, Tasoglou and Pandis (2015); h, Huffman et al. (2009); s, Shilling et al. (2009); k, Kim et al. (2014); z, Zhao et al. (2015); c, Chhabra et al. (2011); 1, Liu et al. (2018).

methods described; see Sect. 2.3.3) rather than the CHNS elemental analyser. A linear relationship $\left(R^{2}=0.9222\right)$ was observed for the $\mathrm{O} / \mathrm{C}$ ratios obtained from UHRMS vs. a CHNS elemental analyser for the $\beta$-caryophyllene SOA samples, suggesting that with further work a possible correction factor could be applied to UHRMS generated SOA O/C ratios to correct for the inaccuracy in the use of a selective ionization source. Further work is required to investigate the accuracy of SOA O/C ratios obtained from UHRMS, including the effect of different SOA precursors, introduction techniques (i.e. liquid chromatography or direct infusion) and data processing methods. This investigation demonstrates the capabilities and use of the CFR, allowing sufficient quantities of SOA mass to be generated in order to evaluate the accuracy of existing techniques.

\subsubsection{NMR spectroscopy}

NMR spectroscopy can provide detailed structural information on the carbon, hydrogen and nitrogen nuclei bonds present in complex mixtures. This technique is complementary to detailed chemical speciation, providing molecularlevel insight into the bulk chemical composition of OA (Chalbot and Kavouras, 2014; Duarte and Duarte, 2011, 2015; Simpson et al., 2012). Proton NMR spectroscopy $\left({ }^{1} \mathrm{H}\right.$ NMR) is the most commonly used NMR technique for the analysis of OA, although numerous alternative nuclei and two-dimensional spin-spin coupling methods exist (see Duarte and Duarte, 2015, for further information). The complexity of OA can reduce the amount of chemical information that can be obtained from ${ }^{1} \mathrm{H}$ NMR analysis. Ambient OA contains thousands of compounds of differing chemical functionalities, which combined with the relatively small dispersion of proton chemical shifts ( 0 to $\sim 10 \mathrm{ppm}$ ), often results in a complex unresolved spectrum with few abundant peaks (Duarte and Duarte, 2011). The binning of spectral regions that correspond to certain functionalities (e.g. aliphatic protons, aromatic protons, etc.) via offline data processing, can aid in the compositional interpretation of bulk OA using ${ }^{1} \mathrm{H}$ NMR analysis (Decesari et al., 2000, 2001) and has been successfully used in several studies (see Chalbot and Kavouras, 2014, and references therein). Two-dimensional NMR spectroscopy, however, can provide increased resolution and additional compositional information in comparison to ${ }^{1} \mathrm{H}$ NMR spectroscopy, although is rarely used within aerosol science due to the large amount of mass required for analysis (>1 mg) (Duarte and Duarte, 2015; Simpson et al., 2012). Here we show, as an example, how the large quantity of SOA mass collected from the CFR can be used to gain greater compositional insights into SOA using twodimensional NMR spectroscopy.

The SOA samples were analysed using ${ }^{1} \mathrm{H}$ and twodimensional ${ }^{1} \mathrm{H}_{-}{ }^{13} \mathrm{C}$ heteronuclear single-quantum correlation (HSQC) NMR spectroscopy. HSQC detects the carbonhydrogen couplings of each bond in a molecular substructure, providing the proton and carbon shifts for both atoms. The ${ }^{1} \mathrm{H}$ and ${ }^{1} \mathrm{H}-{ }^{13} \mathrm{C}$ HSQC NMR spectra of $\beta$-caryophyllene and toluene SOA formed at $55 \%$ relative humidity and $\mathrm{VOC} / \mathrm{NO}_{x}$ ratio of 3 (exps. 31 and 36 Table 1, respectively) are shown in Fig. 6. The ${ }^{1} \mathrm{H}$ NMR spectral regions, as defined in Decesari et al. $(2000,2001)$, are shown in Fig. 6a and c. The ${ }^{1} \mathrm{H}$ NMR spectra of $\beta$-caryophyllene and toluene SOA are vastly different. $\beta$-caryophyllene SOA displays an abundance of aliphatic proton groups $\left(\delta^{1} \mathrm{H} 0.7\right.$ to $3.2 \mathrm{ppm}$ ) with hardly any peaks observed for protons bonded to oxygenated saturated aliphatic carbon atoms $\left(\delta^{1} \mathrm{H} 3.4\right.$ to $4.1 \mathrm{ppm}$ and $\delta^{1} \mathrm{H} 5.0$ to 5.6), confirming the SOA sample is not very oxidized (CHNS data, $\mathrm{O} / \mathrm{C}$ ratio $=0.31$ ). The ${ }^{1} \mathrm{H}$ NMR spectra of toluene SOA displays an abundance of protons bonded to an adjacent aliphatic carboncarbon double bond $\left(\delta^{1} \mathrm{H} 1.9\right.$ to $\left.3.2 \mathrm{ppm}\right)$ and (dissimilar to $\beta$-caryophyllene SOA) oxygenated saturated aliphatic carbon atoms $\left(\delta^{1} \mathrm{H} 3.4\right.$ to $\left.4.1 \mathrm{ppm}\right)$, suggesting the sample contains ring-opened species and is highly oxidized (CHNS data, $\mathrm{O} / \mathrm{C}$ ratio $=0.84)$. In contrast to the ${ }^{1} \mathrm{H}$ NMR spectrum of $\beta$-caryophyllene SOA, toluene SOA displays protons bonded to an aromatic carbon atom (ring-retaining species) and an unresolved low-intensity peak for protons bonded to aliphatic methyl, methylene and/or methyne groups $\left(\delta^{1} \mathrm{H} 0.7\right.$ to $1.9 \mathrm{ppm}$ ).

The ${ }^{1} \mathrm{H}_{-}{ }^{13} \mathrm{C}$ HSQC NMR spectra displays considerably more compositional information than observed in the ${ }^{1} \mathrm{H}$ 

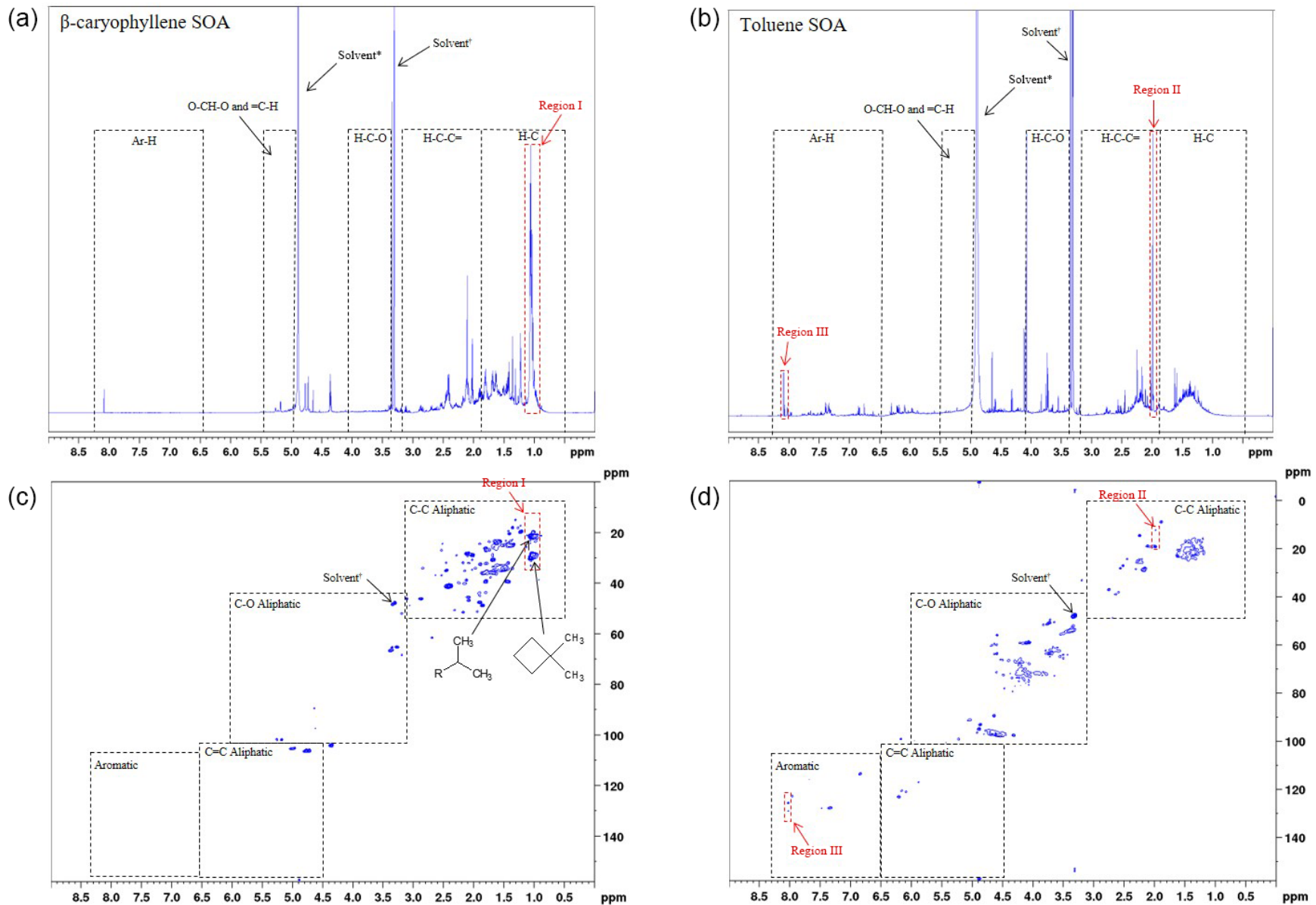

Figure 6. ${ }^{1} \mathrm{H}$ and ${ }^{1} \mathrm{H}_{-}{ }^{13} \mathrm{C}$ HSQC NMR spectra of $\beta$-caryophyllene (a and $\mathbf{b}$, respectively) and toluene (c and $\mathbf{d}$, respectively) SOA formed at $55 \%$ relative humidity with a $\mathrm{VOC} / \mathrm{NO}_{x}$ ratio of 13 (exps. 31 and 36, respectively; see Table 1). The proton spectral regions, as defined in Decesari et al. $(2000,2001)$, are shown in the ${ }^{1} \mathrm{H}$ NMR spectra as dashed black lines. The spectral regions shown in the ${ }^{1} \mathrm{H}-{ }^{13} \mathrm{C}$ HSQC NMR spectra have been adapted from Chen et al. (2016); see the text for further information.

NMR spectra (see Fig. 6). The spectral regions shown in the ${ }^{1} \mathrm{H}_{-}{ }^{13} \mathrm{C}$ HSQC spectra have been adapted from Chen et al. (2016) using a structural carbon-hydrogen coupling predictive tool for known and structurally similar $\beta$ caryophyllene and toluene oxidation products (see Sect. 2.3.2 for further information). The abundant aliphatic protons ( $\delta^{1} \mathrm{H} 0.7$ to $3.2 \mathrm{ppm}$ ), observed in the ${ }^{1} \mathrm{H}$ NMR spectra of $\beta$-caryophyllene SOA (Fig. 6a), display over 40 carbonhydrogen coupling signals in the HSQC spectra (Fig. 6b). The compositional benefits of ${ }^{1} \mathrm{H}_{-}{ }^{13} \mathrm{C}$ HSQC analysis can be observed in region I of Fig. 6a and b. The most abundant peak in the ${ }^{1} \mathrm{H}$ NMR spectrum of $\beta$-caryophyllene SOA is from protons bonded to a methyl group $\left(\delta^{1} \mathrm{H} 1.1 \mathrm{ppm}\right)$. In the ${ }^{1} \mathrm{H}-{ }^{13} \mathrm{C}$ HSQC spectrum, it can be observed that the methyl group at $\delta^{1} \mathrm{H} 1.1 \mathrm{ppm}$ consists of two carbon-hydrogen coupling signals (i.e. the same proton chemical shift but different carbon chemical shifts). The two carbon-hydrogen coupling signals correspond to a methyl group bonded to an adjacent tertiary carbon atom at $\delta^{13} \mathrm{C} 21.2 \mathrm{ppm}$ and an adjacent cyclic carbon atom at $\delta^{13} 29.9 \mathrm{ppm}$, both which are bonded to a neighbouring methyl group (resembling the carbonbackbone structure of $\beta$-caryophyllene). This compositional information cannot be observed in the ${ }^{1} \mathrm{H}$ NMR spectra. Similarly, additional compositional information can be observed in the ${ }^{1} \mathrm{H}^{-13} \mathrm{C}$ HSQC spectrum of toluene SOA. Region II in the ${ }^{1} \mathrm{H}$ NMR spectra displays an abundant aliphatic proton peak at $\delta^{1} \mathrm{H} 2.0 \mathrm{ppm}$. In the HSQC spectrum, two defined carbon-hydrogen coupling signals can be observed. Based on predicted carbon-hydrogen couplings, these two signals likely represent the carbon-hydrogen bonds in the methyl group attached to an aromatic ring with $\left(\delta^{13} \mathrm{C} 19.1\right)$ and without $\left(\delta^{13} \mathrm{C} 12.5 \mathrm{ppm}\right)$ an electronegative aromatic substituent, such as a hydroxyl group, in the meta-position to the methyl group. In addition, region III likely displays aromatic carbon-hydrogen bonds that are in the meta-position to a nitro aromatic substitution; the only aromatic substituent which would result in an adjacent carbon-hydrogen chemical shift of $\delta^{13} \mathrm{C} \sim 125 \mathrm{ppm}$ and $\delta^{1} \mathrm{H} \sim 8 \mathrm{ppm}$, respectively. 
It is imperative to note that predictive carbon-hydrogen coupling tools should only be used as a guide and authentic standards (where possible) should be used to confirm predicted carbon-hydrogen coupling shifts. Nevertheless, the above discussion demonstrates the additional compositional information which can be obtained using two-dimensional NMR spectroscopy. Few studies have used two-dimensional NMR spectroscopy for the compositional analysis of bulk OA. This technique, in combination with the use of a spectral library, has the capability to aid in the interpretation of detailed chemical speciation and provide new insights into the bulk chemical composition of SOA.

\subsubsection{Generating SOA standards}

ESI-UHRMS is capable of providing molecular and structural speciation of individual compounds in complex mixtures and is therefore widely used within aerosol science to determine the detailed chemical speciation of OA (Laskin et al., 2012; Nizkorodov et al., 2011; Pratt and Prather, 2012). The lack of commercially available standards, however, often results in the use of surrogate standards (i.e. structurally and compositionally similar species) for quantification. The use of surrogate standards can have a considerable effect on the reported concentrations when using a selective ionization source, such as ESI. The molecular size, volatility, basicity and polarity of a compound can all affect the ionization response (Kiontke et al., 2016; Oss et al., 2010). Here, we show how the large quantity of SOA mass collected from the CFR can be used to generate SOA standards, reducing the need for additional commercially available standards or chemical synthesis.

Several experiments, in addition to those shown in Table 1, were performed to generate additional SOA mass from the photo-oxidation of $\alpha$-pinene. This additional SOA mass was used to generate standards to quantify components in the SOA mass formed in the $\alpha$-pinene experiments. A similar methodology has previously been used in our group, generating standards from SOA mass formed in a micro-reactor (see Finessi et al., 2014). In total, 17 compounds were targeted in the generated SOA mass. HPLC-ITMS coupled to an automated fraction collector was used to isolate and collect the targeted compounds based on their retention times. The molecular identification of each standard was determined using a combination of the molecular information and fragmentation patterns provided by the UPLC-UHRMS ${ }^{2}$ and the proton chemical shifts obtained from ${ }^{1} \mathrm{H}$ NMR spectroscopy. ${ }^{1} \mathrm{H}$ NMR spectroscopy was used to determine the amount of mass collected for each targeted compound via the integration of the peak integrals of a known proton peak (e.g. a methyl group) and the internal standard (i.e. TSP). Once the concentration of each fraction had been determined, the standard was used for quantification. Major $\alpha$-pinene oxidation products often contain two characteristic methyl groups attached to a cyclic ring (e.g. pinonic acid, pinonaldhyde, pinic acid, 10-hydroxypinonic acid, among others). The characteristic cyclic methyl groups can easily be identified in the ${ }^{1} \mathrm{H}$ NMR spectrum (Finessi et al., 2014). Several of the targeted compounds contained the two characteristic cyclic methyl groups, allowing the concentration of the standard to be determined (via the integration of the methyl protons), even if the entire chemical structure was unclear. Of the 17 targeted compounds, 10 were deemed suitable for use as standards. The other 7 compounds were excluded from further analysis due to an insufficient amount of collected mass and/or their complex spectrum, where the cyclic methyl groups could not be identified preventing the concentration of the standard from being determined. The molecular formulae, retention times and collection times of the 10 standards are shown in Table S2.

A comparison of the chromatographic peaks obtained for both the generated and authentic standard of pinic acid at a concentration of $1 \mathrm{ppm}$ is shown in Fig. S3. From Fig. S3, it can be observed that both chromatographic peaks display relatively good agreement, with similar peak shapes and ion intensities observed ( $10 \%$ difference in peak area). In addition to the 10 targeted compounds, $4 \alpha$-pinene standards which were generated in Finessi et al. (2014) and 2 commercially available compounds (i.e. pinic acid and cis-pinonic acid) were used to identify and quantify components in the $\alpha$-pinene SOA samples using UPLC-UHRMS. An identification was confirmed if a compound in the SOA sample displayed the same molecular formula $(<2 \mathrm{ppm}$ error $)$, retention time $( \pm 30 \mathrm{~s})$ and fragmentation patterns as the standard. Calibrations were performed for all of the compounds shown in Table S2, with the exception of compound 5, where the authentic pinic acid standard was used instead. Calibrations ranged from 0.001 to $15 \mathrm{ppm}$ with a minimum of four concentrations and three replicate measurements per concentration. The total amount of SOA mass quantified in each experiment is shown in Fig. 7. The standards represented up to $35.8 \pm 1.6 \%$ of the total $\alpha$-pinene SOA mass. The error represents the propagated uncertainty in the slope of each calibration graph used for quantification. The quantified $\alpha$-pinene SOA mass varied considerably depending on the experimental conditions. The average amount of $\alpha$-pinene SOA mass quantified in the no $\mathrm{NO}_{x}$ and $\mathrm{NO}_{x}$ experiments was $6.9 \%$ and $33.2 \%$, respectively. The targeted standards were selected in $\alpha$-pinene SOA formed under $\mathrm{NO}_{x}$ conditions, likely accounting for the larger amount of SOA mass quantified in the $\mathrm{NO}_{x}$ experiments. Molecular speciation techniques typically quantify $<25 \%$ of OA mass (Hallquist et al., 2009; Nozière et al., 2015). Using the techniques described, considerable improvements can be made in the total amount of SOA mass quantified. 


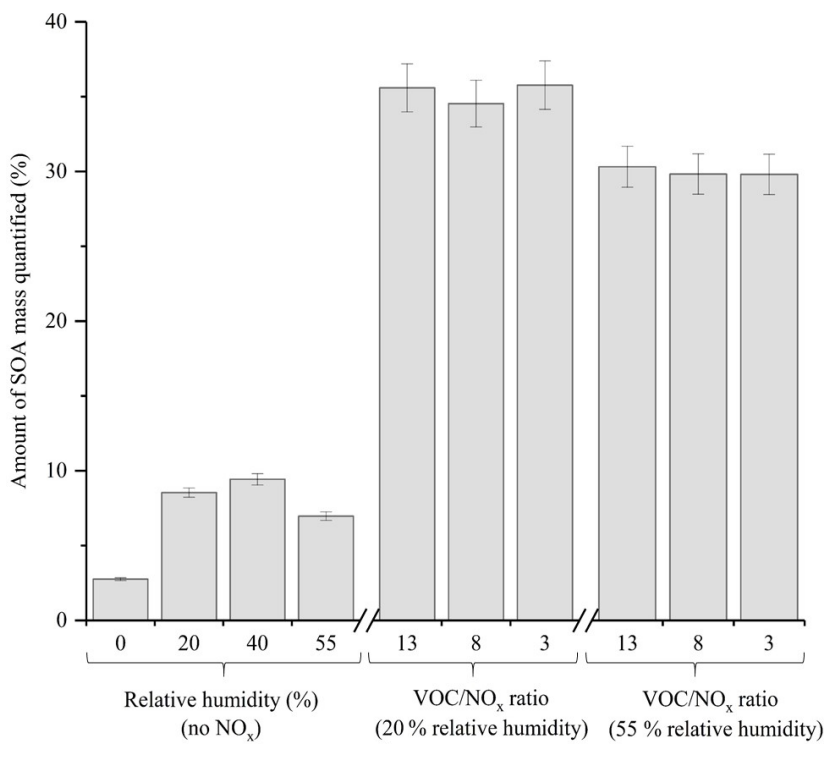

Figure 7. Total amount of SOA mass quantified using the generated standards in the $\alpha$-pinene experiments shown in Table 1. Error bars represent the propagated uncertainty in the slope of the calibrations used to quantify each SOA component.

\subsubsection{Chemical and physical properties of SOA single particles}

SOA can exist in highly viscous semi-solid and solid states, depending on chemical composition and the conditions of the surrounding gas phase ( $T$ and $\mathrm{RH}$ ); the phase state of SOA particles affects the diffusion rates of molecules within the aerosol phase, affecting physicochemical processes such as the partitioning of organic species between the condensed and gas phases, heterogeneous chemical reactions, and ice nucleation (Reid et al., 2018). As indicated by Shrivastava et al. (2017), there is the need for a systematic investigation of the viscosity of SOA and its effects on the physicochemical properties of SOA particles as a function of $\mathrm{T}$ and $\mathrm{RH}$ and for SOA formed from different precursors at variable $\mathrm{NO}_{x}$ and $\mathrm{RH}$ conditions. The CFR experiments presented in this work, coupled with the thorough information on the SOA chemical composition (Sect. 3.2.1-3.2.3) and the single-particle experiments described below, represent a unique opportunity for such a systematic investigation.

As an example of the capabilities of the single-particle EDB approach to elucidate the physiochemical properties of the SOA samples, we report in Fig. 8 a comparison of the volatility of $\beta$-caryophyllene (exps. 28; see Table 1 ) and toluene SOA (exp. 35) formed in the CFR at $55 \% \mathrm{RH}$ with no $\mathrm{NO}_{x}$. Once a diluted SOA droplet is initially trapped (typical initial SOA extract mass fraction of $\sim 0.02$ ), a steep decrease in size is observed, with both water and ethanol evaporating to reach equilibrium with the gas-phase composition (timescale of less than $10 \mathrm{~s}$ at $293 \mathrm{~K}$ ). No ethanol is present in the gas phase, and therefore it evaporates completely from

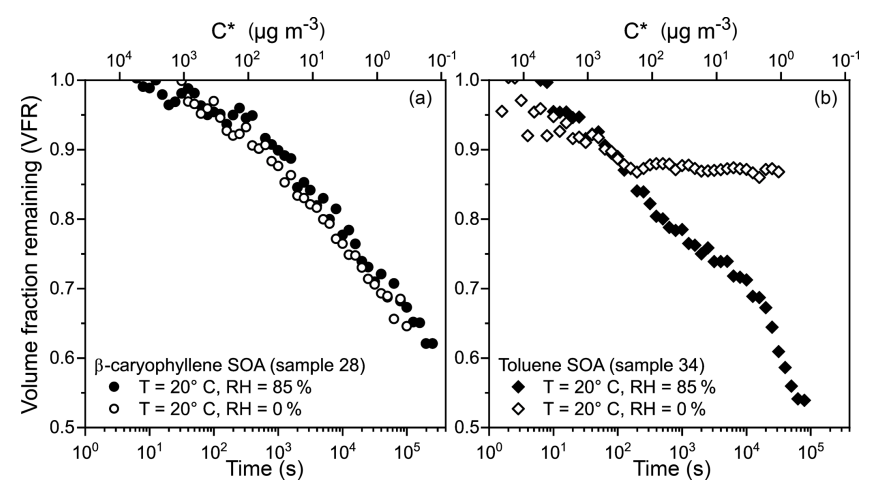

Figure 8. Volume fraction remaining (VFR) for single $\beta$ caryophyllene SOA (a) and toluene SOA (b) droplets confined in an electrodynamic balance (EDB) over $\sim 1 \mathrm{~d}$. VFR is compared for evaporation into high RH (solid symbols) and dry conditions (open symbols). Sample numbers correspond to the experiments shown in Table 1 . The secondary $x$ axis displays the calculated effective saturation concentration $\left(C^{*}, \mu \mathrm{g} \mathrm{m}^{-3}\right)$; see text for further information.

the droplet; by contrast, the water content in the condensed phase equilibrates such that the water activity in solution is equal to that of the gas phase. After this rapid evaporation phase, the radius of SOA-trapped single droplets is generally observed to decrease slowly over time, with the semivolatile organic components within the droplets partitioning to the gas phase together with the solvating water. In Fig. 8, the loss of these organic components (and solvating water) is represented as a volume fraction remaining (VFR) compared to the "initial" droplet volume once the initial loss and equilibration of water content has occurred, identified as the point where the rapid water and ethanol evaporation is concluded (typical initial reference radius of $\sim 5-8 \mu \mathrm{m}$ ). To report the VFR values in Fig. 8, the measured radii were separated into bins, each corresponding to a $\log _{10}($ time $)=0.1$ interval and then averaged.

Figure 8a compares VFR data for two $\beta$-caryophyllene SOA particles evaporating into high RH and dry conditions. In both cases, the VFR decreases with time, indicating a mass loss from the particle, due to the volatilisation of organic species, and the two curves present a similar trend. The activity of the organic species at $0 \% \mathrm{RH}$ is expected to be higher than at $85 \% \mathrm{RH}$, a consequence of the absence of condensedphase water and a higher concentration of the organic components, although a faster evaporation rate would be expected under dry conditions compared to wet conditions. As a result, the two time dependencies in the VFR data sets in Fig. 8a show a very similar trend. This can likely be explained by a kinetic limitation on the diffusion of the organic components within the $\beta$-caryophyllene SOA particle at $0 \% \mathrm{RH}$, due to high viscosity. Indeed, $\mathrm{Li}$ et al. (2015) measured a transition of $\beta$-caryophyllene SOA particles from liquid to non-liquid at a $\mathrm{RH}$ above $90 \%$ from particle bounce experiments, supporting the hypothesis that a high viscosity is re- 
stricting the rate of volatilisation from the $\beta$-caryophyllene SOA particle at low RH. The secondary $x$ axis in Fig. 8 represents an estimate of the evolving effective saturation concentration $\left(C^{*}\right)$ for a $7 \mu \mathrm{m}$ droplet, calculated according to Donahue et al. (2006) and assuming a diffusion coefficient of $10^{-6} \mathrm{~m}^{2} \mathrm{~s}^{-1}$, a molecular mass of $200 \mathrm{~g} \mathrm{~mol}^{-1}$ and a density of $1.4 \mathrm{~g} \mathrm{~m}^{-3}$. This calculation provides an estimate of the lifetime of each of the indicated $C^{*}$ bins in the case of no kinetic limitations to the evaporation of the organic molecules. For example, organic molecules in the $10^{2} \mu \mathrm{g} \mathrm{m}^{-3}$ bin are expected to have a lifetime in the condensed phase $<1000 \mathrm{~s}$ and at the end of the experimental timescale $\left(\sim 10^{5} \mathrm{~s}\right)$, only molecules with $C^{*}$ lower than $10^{-1} \mu \mathrm{g} \mathrm{m}^{-3}$ are still present in the evaporating droplet.

When compared to $\beta$-caryophyllene SOA, toluene SOA particles present a very different VFR profile (Fig. 8b): significant evaporation of the trapped particle is observed at high $\mathrm{RH}$, but the evaporative loss of semi-volatiles appears completely inhibited at $0 \% \mathrm{RH}$ after $\sim 10^{2} \mathrm{~s}$, with the particle size achieving a constant value. Similarly, but more markedly when compared to the $\beta$-caryophyllene SOA case, this complete inhibition of the volatilisation of organic components from the condensed phase is caused by the high viscosity of the toluene SOA particle at $0 \% \mathrm{RH}$. Song et al. (2016) inferred a lower limit of viscosity for toluene SOA below $17 \% \mathrm{RH}$ of $\sim 5 \times 10^{8} \mathrm{Pas}$; the observation of strong kinetic limitation to evaporation shown in Fig. 8b is consistent with such high viscosity. The difference in VFR after $10^{5} \mathrm{~s}$ between particles held at wet and dry conditions is significant $(\sim 0.35)$ and it is a clear indication that the size of toluene SOA particles strongly depends on their phase state (liquid vs. semi-solid). In a future paper, we will provide a comprehensive analysis of all volatilisation measurements, reporting the volatility and viscosity distribution that characterize the various SOA samples in this work by using the KM-GAP model (Yli-Juuti et al., 2017) to analyse the experimental data.

\subsection{CFR limitations}

A comparison of the bulk chemical functionalities observed in two SOA samples formed from the photo-oxidation of $\alpha$-pinene, with a VOC mixing ratio of $18.5 \mathrm{ppmv}$ (exp. 10) and 2.1 ppmv (exp. 14) are shown in Fig. S4. The bulk SOA chemical functionalities were determined using ATR-FTIR spectroscopy. Both experiments were performed at $55 \%$ relative humidity with a $\mathrm{VOC} / \mathrm{NO}_{x}$ ratio of 3 . The peak heights of the individual chemical functionalities were normalized to the total peak height of all speciated chemical functionalities in each SOA sample, allowing a direct comparison between samples. It is worth noting that a second low $\alpha$-pinene mixing ratio experiment was performed (exp. 7; see Table 1). However, this SOA sample displayed poor spectral absorption in all three replicate measurements, the reason for which is unclear. Subsequently, this sample has been excluded from the following discussion. From Fig. S4, it can be observed that the aromatic nitro, nitrate and aliphatic functionalities in both SOA samples display relatively good agreement. However, hydroxyl and carbonyl functionalities display some disagreement. The SOA formed from the low $\alpha$-pinene mixing ratio experiment $(2.1 \mathrm{ppmv})$ contained increased hydroxyl functionality $(\sim 12 \%)$ and decreased carbonyl functionality ( $\sim 11 \%$ ), in comparison to the SOA formed from the high $\alpha$-pinene mixing ratio experiment (18.5 ppmv). This discrepancy is likely due to the partitioning of higher-volatility species into the particulate phase with the use of higher VOC mixing ratios (Donahue et al., 2006; Pankow, 1994a, b), affecting the observed chemical functionality. The bulk elemental composition, however, did not appear to be largely affected by the use of high VOC mixing ratios (see Sect. 3.2.1). Nevertheless, future studies using lower mixing ratios and extended sampling times could be used to overcome this.

The CFR was designed as a simple, low-cost tool to generate large quantities of SOA mass for offline composition and single-particle analysis. The high VOC and oxidant mixing ratios (i.e. parts-per-million by volume levels) used in study may increase the possibility of reactive nitrogen species interacting with the SOA via heterogenous processes, affecting the observed SOA chemical composition (e.g. MontoyaAguilera et al., 2018). Furthermore, there is a strong possibility of artefacts from gas-phase adsorption to the quartz fibre filters (Parshintsev et al., 2011). Gas-phase adsorption to the ELPI is negligible due to its design (i.e. particles are collected onto size-segregated impactor plates (based on their aerodynamic size), whilst under a strong low vacuum that continuously removes gas-phase species). All compositional and single-particle analysis techniques were performed on the SOA collected from the ELPI, with the exception of infrared spectroscopy, which was performed on the SOA collected onto the quartz fibre filters. Thus, it is possible that the quartz fibre filters analysed using infrared spectroscopy may be affected by artefacts. Future studies should use an activated charcoal trap prior to the quartz fibre filter to prevent gas-phase absorption. The offline techniques used in this study are unlikely to introduce a major source of artefacts into the samples, providing instrument background or blank runs are performed and the contaminants subtracted from the sample data, as performed in this work. Artefacts are more commonly introduced into the samples through preparation methods (e.g. filter extraction processes) for analysis using offline techniques. The use of the ELPI minimized the potential introduction of artefacts into the samples through the exclusion of all extraction processes, i.e. samples were either analysed without modification or dissolved into high-purity solvents (without temperature or pressure changes).

The UV lamps used in the CFR had light emissions with wavelengths at $254 \mathrm{~nm}$ (primary energy) and $185 \mathrm{~nm}$. The $185 \mathrm{~nm}$ wavelength may result in very different organic radical chemistry than observed in the ambient atmosphere (see Peng et al., 2016, for further information), potentially affect- 
ing the observed SOA composition. In addition, the light intensity emitted from the UV lamps was not sufficient for the reactor size, resulting in photochemically dark space within the reactor. It is strongly recommended that the UV light source is modified in future studies. This is of the upmost importance for applications focused on replicating atmospheric conditions. Multiple non-emitting $185 \mathrm{~nm}$ wavelength UV lamps should be installed into the reactor housing (possibly on all four panels) and the UV emissions experimentally characterized, ensuring the light distribution within the reactor is as uniform as possible, increasing the atmospheric relevance of the generated SOA. It must be stressed, however, that the objective of this study was to investigate the effect of chemical composition on the physical state of the generated SOA, furthering our understanding of the physicochemical relationship controlling gas-particle partitioning. These physiochemical relationships are determined by the chemical and physical properties of each SOA sample and are not affected by the atmospheric relevance of generated SOA.

\section{Conclusions}

This study describes the design and operation of a newly built $0.3 \mathrm{~m}^{3}$ CFR which can be used as a tool to gain greater insights into the composition and physical state of SOA. The CFR was used to generate SOA mass from the photo-oxidation of $\alpha$-pinene, limonene, $\beta$-caryophyllene and toluene under different experimental conditions. The design and operation of the CFR allowed $>10^{2} \mathrm{mg}$ of SOA mass to be collected per experiment. The considerable quantities of SOA mass collected in each experiment allowed the use of highly accurate compositional and single-particle analysis techniques which are not usually accessible, due to the large amount of OA mass required for analysis. Four techniques were presented (as examples) to demonstrate the additional compositional and physical state information that can be obtained using the methods outlined in this paper. The four techniques included (i) the use of a highly accurate CHNS elemental analyser to determine the elemental composition of the generated SOA samples and the ability to evaluate the accuracy of reported elemental compositions using a commonly used technique (UHRMS), (ii) the additional compositional information that can be obtained using two-dimensional NMR spectroscopy, (iii) the generation of SOA standards, overcoming the analytical challenges associated with the lack of commercially available standards, and (iv) the first use of an electrodynamic balance to assess the influence of the temperature and phase state of the SOA on the volatilisation kinetics of semi-volatile components from a sample particle. High VOC mixing ratios (parts-per-million by volume levels) were used in this study to generate sufficient quantities of SOA mass for offline analysis. The investigation of two replicate experiments using different $\alpha$ pinene mixing ratios (18.5 and $2.1 \mathrm{ppmv}$ ) did display a slight discrepancy ( $\sim 11 \%$ difference) in bulk SOA hydroxyl and carbonyl functionalities, possibly a result of the high VOC mixing ratios used. However, aliphatic, nitrate and aromatic nitro functionalities all displayed relatively good agreement. It is important to note that the objective of this study was not to mimic atmospheric conditions but to provide a tool that allowed the use of highly accurate techniques to gain greater insights into the chemical and physical properties of SOA. Nevertheless, the elemental composition of the generated SOA displayed good agreement with literature values, suggesting that, for the experimental conditions investigated, the bulk elemental composition is largely unaffected by the use of high VOC mixing ratios. The SOA generated from two replicate experiments displayed excellent agreement, with measured $\mathrm{O} / \mathrm{C}$ and $\mathrm{H} / \mathrm{C}$ ratios within the error of the analytical instrumentation. Using the methods described, we were able to quantify up to $36 \%$ of $\alpha$-pinene SOA, which is a considerable improvement from most previous studies. We must stress that the developed CFR design will require modification to the UV light source for applications focused on replicating atmospheric conditions. The current UV light source is not sufficient for the reactor size, resulting in photochemically dark space within the reactor. The CFR costs GBP $\sim 8000$ to build, including the reactor housing. A considerable proportion of this cost is attributed to use of several mass flow controllers costing GBP $\sim 6500$. The mass flow controllers can be substituted for cheaper alternatives (e.g. ball flow meters), which will significantly reduce the cost. However, due to the reduced accuracy in the flow rates of these alternatives methods, the CFR will need to be operated at low flow rates (less than $\sim 4 \mathrm{~L} \mathrm{~m}^{-1}$ ) and the reactor volume closely monitored. The CFR is incredibly versatile. Multiple instruments can be connected to the reactor and easily interchanged. Different oxidants and/or scavengers can be introduced into the reactor and mixed VOC experiments can be performed (i.e. introduction of two VOCs). The CFR can also be designed to be more sophisticated with a simple addition of a software program (using DAQFactory, or similar) for the automated control of the mass flow controllers. This work demonstrates how the unconventional use of a newly built CFR can be used to gain considerable insights into the chemical and physical properties of SOA, providing a greater understanding of the relationship between SOA formation conditions, chemical composition and physicochemical properties.

Data availability. The unprocessed ATR-FTIR, ${ }^{1} \mathrm{H}$, and ${ }^{1} \mathrm{H}_{-}{ }^{13} \mathrm{C}$ HSQC NMR and EDB data, shown in Figs. 4, 6, and 8, and the tabulated data used to plot Figs. 5 and 7 have been provided in a data depository; see the University of York research database PURE (https://doi.org/10.15124/282966e4-c1694235-94b2-07a4b936f5cd, Pereira et al., 2019). 
Supplement. The supplement related to this article is available online at: https://doi.org/10.5194/amt-12-4519-2019-supplement.

Author contributions. KP designed, built, and operated the CFR; designed the experiments; collected and distributed the SOA samples; performed all compositional analysis and associated data interpretation; and wrote the manuscript. AM aided KP in the collection, evaporation and ${ }^{1} \mathrm{H}$ NMR preparation of the $\alpha$-pinene fractions. JH was responsible for the conceptualization and funding acquisition of the York component of the project and supervised KP's work. GR was responsible for the single-particle analysis and data interpretation of the SOA samples at the University of Bristol. YS assisted GR with the single-particle analysis and data interpretation. JR was responsible for the conceptualization and funding acquisition of the Bristol component of the project, co-ordinated the research activity planning and execution of the whole project (lead PI) and supervised the work performed by GR and YS. All authors contributed to the manuscript.

Competing interests. The authors declare that they have no conflict of interest.

Acknowledgements. The $\mathrm{NO}_{x}$ and $\mathrm{O}_{3}$ analysers used in this work were provided by Katie Read, University of York, through the Atmospheric Measurement Facility (AMF); a facility housed at the Wolfson Atmospheric Chemistry Laboratories (WACL) and funded through the National Centre for Atmospheric Science (NCAS).

Financial support. This research has been supported by the Natural Environment Research Council (grant no. NE/M002411/1). The Orbitrap was funded by a Natural Environment Research Council strategic capital grant CC090.

Review statement. This paper was edited by Mingjin Tang and reviewed by four anonymous referees.

\section{References}

Ahlberg, E., Falk, J., Eriksson, A., Holst, T., Brune, W. H., Kristensson, A., Roldin, P., and Svenningsson, B.: Secondary organic aerosol from VOC mixtures in an oxidation flow reactor, Atmos. Environ., 161, 210-220, 2017.

Anttila, T., Lehtinen, K. E. J., and Dal Maso, M.: Analytical expression for gas-particle equilibration time scale and its numerical evaluation, Atmos. Environ., 133, 34-40, 2016.

Bateman, A. P.; Nizkorodov, S. A.; Laskin, J.; Laskin, A., Timeresolved molecular characterization of limonene/ozone aerosol using high-resolution electrospray ionization mass spectrometry, Phys. Chem. Chem. Phys., 11, 7931-7942, 2009.

Bateman, A. P., Bertram, A. K., and Martin, S. T.: Hygroscopic Influence on the Semisolid-to-Liquid Transition of Secondary Organic Materials, J. Phys. Chem. A, 119, 4386-4395, 2015.
Bharti, S. K. and Roy, R.: Quantitative 1H NMR spectroscopy, TRAC-Trend. Anal. Chem., 35, 5-26, 2012.

Bloss, C., Wagner, V., Bonzanini, A., Jenkin, M. E., Wirtz, K. Martin-Reviejo, M., and Pilling, M. J.: Evaluation of detailed aromatic mechanisms (MCMv3 and MCMv3.1) against environmental chamber data, Atmos. Chem. Phys., 5, 623-639, https://doi.org/10.5194/acp-5-623-2005, 2005.

Bruns, E. A., El Haddad, I., Keller, A., Klein, F., Kumar, N. K., Pieber, S. M., Corbin, J. C., Slowik, J. G., Brune, W. H., Baltensperger, U., and Prévôt, A. S. H.: Inter-comparison of laboratory smog chamber and flow reactor systems on organic aerosol yield and composition, Atmos. Meas. Tech., 8, 23152332, https://doi.org/10.5194/amt-8-2315-2015, 2015.

Canagaratna, M. R., Jimenez, J. L., Kroll, J. H., Chen, Q., Kessler, S. H., Massoli, P., Hildebrandt Ruiz, L., Fortner, E., Williams, L. R., Wilson, K. R., Surratt, J. D., Donahue, N. M., Jayne, J. T., and Worsnop, D. R.: Elemental ratio measurements of organic compounds using aerosol mass spectrometry: characterization, improved calibration, and implications, Atmos. Chem. Phys., 15, 253-272, https://doi.org/10.5194/acp-15-253-2015, 2015.

Cao, G., Yan, Y., Zou, X., Zhu, R., and Ouyang, F.: Applications of Infrared Spectroscopy in Analysis of Organic Aerosols, Spectral Analysis Review 2018, 6, 2018

Carter, W., Atkinson, R., Winer, A., and Pitts, J.: Evidence for chamber-dependent radical sources: Impact on kinetic computer models for air pollution, Int. J. Chem. Kinet., 13, 735-740, 1981.

Carter, W., Atkinson, R., Winer, A., and Pitts, J.: Experimental investigation of chamber-dependent radical sources, Int. J. Chem. Kinet., 14, 1071-1103, 1982.

Chhabra, P. S., Ng, N. L., Canagaratna, M. R., Corrigan, A. L., Russell, L. M., Worsnop, D. R., Flagan, R. C., and Seinfeld, J. H.: Elemental composition and oxidation of chamber organic aerosol, Atmos. Chem. Phys., 11, 8827-8845, https://doi.org/10.5194/acp-11-8827-2011, 2011.

Chalbot, M.-C. G. and Kavouras, I. G.: Nuclear magnetic resonance spectroscopy for determining the functional content of organic aerosols: A review, Environ. Pollut., 191, 232-249, 2014.

Chen, Q., Heald, C. L., Jimenez, J. L., Canagaratna, M. R., Zhang, Q., He, L. Y., Huang, X. F., Campuzano-Jost, P., Palm, B. B., Poulain, L., Kuwata, M., Martin, S. T., Abbatt, J. P. D., Lee, A. K. Y., and Liggio, J.: Elemental composition of organic aerosol: The gap between ambient and laboratory measurements, Geophys. Res. Lett., 42, 4182-4189, 2015.

Chen, W., McClelland, D. J., Azarpira, A., Ralph, J., Luo, Z., and Huber, G. W.: Low temperature hydrogenation of pyrolytic lignin over Ru/TiO2: 2D HSQC and 13C NMR study of reactants and products, Green Chem., 18, 271-281, 2016.

Cocker, D. R., Flagan, R. C., and Seinfeld, J. H.: State-of-the-art chamber facility for studying atmospheric aerosol chemistry, Environ. Sci. Technol., 35, 2594-2601, 2001.

Cotterell, M., Mason, B. J., Preston, T. C., Orr-Ewing, A., and Reid, J. P.: Optical Extinction Efficiency Measurements on Fine and Accumulation Mode Aerosol Using Single Particle Cavity Ring-Down Spectroscopy, Phys. Chem. Chem. Phys., 17, 1584315856, https://doi.org/10.1039/C5CP00252D, 2015.

Coury, C. and Dillner, A. M.: ATR-FTIR characterization of organic functional groups and inorganic ions in ambient aerosols at a rural site, Atmos. Environ., 43, 940-948, 2009. 
Czoschke, N. M., Jang, M., and Kamens, R. M.: Effect of acidic seed on biogenic secondary organic aerosol growth, Atmos. Environ., 37, 4287-4299, 2003.

Davies, J. F., Haddrell, A. E., and Reid, J. P.: Time-Resolved Measurements of the Evaporation of Volatile Components from Single Aerosol Droplets, Aerosol Sci. Tech., 46, 666-677, 2012.

Decesari, S., Facchini, M. C., Fuzzi, S., and Tagliavini, E.: Characterization of water-soluble organic compounds in atmospheric aerosol: A new approach, J. Geophys. Res.-Atmos., 105, 14811489,2000

Decesari, S., Facchini, M. C., Matta, E., Lettini, F., Mircea, M., Fuzzi, S., Tagliavini, E., and Putaud, J. P.: Chemical features and seasonal variation of fine aerosol water-soluble organic compounds in the Po Valley, Italy, Atmos. Environ., 35, 3691-3699, 2001

DeRieux, W.-S. W., Li, Y., Lin, P., Laskin, J., Laskin, A., Bertram, A. K., Nizkorodov, S. A., and Shiraiwa, M.: Predicting the glass transition temperature and viscosity of secondary organic material using molecular composition, Atmos. Chem. Phys., 18, 6331-6351, https://doi.org/10.5194/acp-18-6331-2018, 2018.

Donahue, N., Robinson, A., Stanier, C., and Pandis, S.: Coupled partitioning, dilution, and chemical aging of semivolatile organics, Environ. Sci. Technol., 40, 2635-2643, 2006.

Duarte, R. M. B. O. and Duarte, A. C.: A critical review of advanced analytical techniques for water-soluble organic matter from atmospheric aerosols, TRAC-Trend. Anal. Chem., 30, 1659-1671, 2011.

Duarte, R. M. B. O. and Duarte, A. C.: Unraveling the structural features of organic aerosols by NMR spectroscopy: a review, Magn. Reson. Chem., 53, 658-666, 2015.

EAI: Exeter Analytical, available at: http://www.exeteranalytical. co.uk/ce440-specifications/, last access: 27 November 2018

Eluri, S., Cappa, C. D., Friedman, B., Farmer, D. K., and Jathar, S. H.: Modeling the formation and composition of secondary organic aerosol from diesel exhaust using parameterized and semiexplicit chemistry and thermodynamic models, Atmos. Chem. Phys., 18, 13813-13838, https://doi.org/10.5194/acp-18-138132018, 2018.

Finessi, E., Lidster, R. T., Whiting, F., Elliott, T., Alfarra, M. R., McFiggans, G. B., and Hamilton, J. F.: Improving the Quantification of Secondary Organic Aerosol Using a Microflow Reactor Coupled to HPLC-MS and NMR to Manufacture Ad Hoc Calibration Standards, Anal. Chem., 86, 11238-11245, 2014.

Friedman, B. and Farmer, D. K.: SOA and gas phase organic acid yields from the sequential photooxidation of seven monoterpenes, Atmos. Environ., 187, 335-345, 2018.

Gao, S., Keywood, M., Ng, N. L., Surratt, J., Varutbangkul, V., Bahreini, R., Flagan, R. C., and Seinfeld, J. H.: Low-MolecularWeight and Oligomeric Components in Secondary Organic Aerosol from the Ozonolysis of Cycloalkenes and $\alpha$-Pinene, J. Phys. Chem. A, 108, 10147-10164, 2004.

Gaston, C. J., Riedel, T. P., Zhang, Z., Gold, A., Surratt, J. D., and Thornton, J. A.: Reactive Uptake of an Isoprene-Derived Epoxydiol to Submicron Aerosol Particles, Environ. Sci. Technol., 48, 11178-11186, 2014.

George, I. J. and Abbatt, J. P. D.: Chemical evolution of secondary organic aerosol from $\mathrm{OH}$-initiated heterogeneous oxidation, Atmos. Chem. Phys., 10, 5551-5563, https://doi.org/10.5194/acp10-5551-2010, 2010a.
George, I. J. and Abbatt, J. P. D.: Heterogeneous oxidation of atmospheric aerosol particles by gas-phase radicals, Nat. Chem., 2, 713-722, 2010b.

Glantschnig, W. J. and Chen, S.-H.: Light scattering from water droplets in the geometrical optics approximation, Appl. Opt., 20, 2499-2509, 1981.

Glowacki, D. R., Goddard, A., Hemavibool, K., Malkin, T. L., Commane, R., Anderson, F., Bloss, W. J., Heard, D. E., Ingham, T., Pilling, M. J., and Seakins, P. W.: Design of and initial results from a Highly Instrumented Reactor for Atmospheric Chemistry (HIRAC), Atmos. Chem. Phys., 7, 53715390, https://doi.org/10.5194/acp-7-5371-2007, 2007.

Goldstein, A. H. and Galbally, I. E.: Known and unexplored organic constituents in the earth's atmosphere, Environ. Sci. Technol., 41, 1514-1521, 2007.

Grieshop, A. P., Donahue, N. M., and Robinson, A. L.: Is the gas-particle partitioning in alpha-pinene secondary organic aerosol reversible?, Geophys. Res. Lett., 34, https://doi.org/10.1029/2007GL029987, 2007.

Hallquist, M., Wenger, J. C., Baltensperger, U., Rudich, Y., Simpson, D., Claeys, M., Dommen, J., Donahue, N. M., George, C., Goldstein, A. H., Hamilton, J. F., Herrmann, H., Hoffmann, T., Iinuma, Y., Jang, M., Jenkin, M. E., Jimenez, J. L., Kiendler-Scharr, A., Maenhaut, W., McFiggans, G., Mentel, Th. F., Monod, A., Prévôt, A. S. H., Seinfeld, J. H., Surratt, J. D., Szmigielski, R., and Wildt, J.: The formation, properties and impact of secondary organic aerosol: current and emerging issues, Atmos. Chem. Phys., 9, 5155-5236, https://doi.org/10.5194/acp9-5155-2009, 2009.

Hamilton, J. F., Rami Alfarra, M., Wyche, K. P., Ward, M. W., Lewis, A. C., McFiggans, G. B., Good, N., Monks, P. S., Carr, T., White, I. R., and Purvis, R. M.: Investigating the use of secondary organic aerosol as seed particles in simulation chamber experiments, Atmos. Chem. Phys., 11, 5917-5929, https://doi.org/10.5194/acp-11-5917-2011, 2011.

Heald, C., Kroll, J., Jimenez, J., Docherty, K., DeCarlo, P., Aiken, A., Chen, Q., Martin, S., Farmer, D., and Artaxo, P.: A simplified description of the evolution of organic aerosol composition in the atmosphere, Geophys. Res. Lett., 37, https://doi.org/10.1029/2010GL042737, 2010.

Heaton, K. J., Dreyfus, M. A., Wang, S., and Johnston, M. V.: Oligomers in the Early Stage of Biogenic Secondary Organic Aerosol Formation and Growth, Environ. Sci. Technol., 41, 6129-6136, 2007.

Hodshire, A. L., Palm, B. B., Alexander, M. L., Bian, Q., Campuzano-Jost, P., Cross, E. S., Day, D. A., de Sá, S. S., Guenther, A. B., Hansel, A., Hunter, J. F., Jud, W., Karl, T., Kim, S., Kroll, J. H., Park, J.-H., Peng, Z., Seco, R., Smith, J. N., Jimenez, J. L., and Pierce, J. R.: Constraining nucleation, condensation, and chemistry in oxidation flow reactors using size-distribution measurements and aerosol microphysical modeling, Atmos. Chem. Phys., 18, 12433-12460, https://doi.org/10.5194/acp-1812433-2018, 2018.

Huang, W., Saathoff, H., Pajunoja, A., Shen, X., Naumann, K.H., Wagner, R., Virtanen, A., Leisner, T., and Mohr, C.: $\alpha$ Pinene secondary organic aerosol at low temperature: chemical composition and implications for particle viscosity, Atmos. Chem. Phys., 18, 2883-2898, https://doi.org/10.5194/acp18-2883-2018, 2018. 
Huang, Y., Coggon, M. M., Zhao, R., Lignell, H., Bauer, M. U., Flagan, R. C., and Seinfeld, J. H.: The Caltech Photooxidation Flow Tube reactor: design, fluid dynamics and characterization, Atmos. Meas. Tech., 10, 839-867, https://doi.org/10.5194/amt10-839-2017, 2017.

Huffman, J. A., Docherty, K. S., Mohr, C., Cubison, M. J., U1brich, I. M., Ziemann, P. J., Onasch, T. B., and Jimenez, J. L.: Chemically-Resolved Volatility Measurements of Organic Aerosol from Different Sources, Environ. Sci. Tech., 43, 53515357, 2009.

Ihalainen, M., Tiitta, P., Czech, H., Yli-Pirilä, P., Hartikainen, A., Kortelainen, M., Tissari, J., Stengel, B., Sklorz, M., Suhonen, H., Lamberg, H., Leskinen, A., Kiendler-Scharr, A., Harndorf, H., Zimmermann, R., Jokiniemi, J., and Sippula, O.: A novel high-volume Photochemical Emission Aging flow tube Reactor (PEAR), Aerosol Sci. Tech., 53, 276-294, 2019.

Iinuma, Y., Böge, O., Gnauk, T., and Herrmann, H.: Aerosolchamber study of the $\alpha$-pinene $/ \mathrm{O}_{3}$ reaction: influence of particle acidity on aerosol yields and products, Atmos. Environ., 38, 761-773, 2004.

Jang, M., Czoschke, N. M., Lee, S., and Kamens, R. M.: Heterogeneous Atmospheric Aerosol Production by Acid-Catalyzed Particle-Phase Reactions, Science, 298, 814-817, 2002.

Kalberer, M., Paulsen, D., Sax, M., Steinbacher, M., Dommen, J., Prevot, A., Fisseha, R., Weingartner, E., Frankevich, V., and Zenobi, R.: Identification of polymers as major components of atmospheric organic aerosols, Science, 303, 1659-1662, 2004.

Kanakidou, M., Seinfeld, J. H., Pandis, S. N., Barnes, I., Dentener, F. J., Facchini, M. C., Van Dingenen, R., Ervens, B., Nenes, A., Nielsen, C. J., Swietlicki, E., Putaud, J. P., Balkanski, Y., Fuzzi, S., Horth, J., Moortgat, G. K., Winterhalter, R., Myhre, C. E. L., Tsigaridis, K., Vignati, E., Stephanou, E. G., and Wilson, J.: Organic aerosol and global climate modelling: a review, Atmos. Chem. Phys., 5, 1053-1123, https://doi.org/10.5194/acp-5-10532005, 2005.

Kidd, C., Perraud, V., Wingen, L. M., and Finlayson-Pitts, B. J.: Integrating phase and composition of secondary organic aerosol from the ozonolysis of $\alpha$-pinene, P. Natl. Acad. Sci. USA, 111, 7552-7557, https://doi.org/10.1073/pnas.1322558111, 2014.

Kim, H., Liu, S., Russell, L. M., and Paulson, S. E.: Dependence of Real Refractive Indices on O:C, H:C and Mass Fragments of Secondary Organic Aerosol Generated from Ozonolysis and Photooxidation of Limonene and $\alpha$-Pinene, Aerosol Sci. Tech., 48, 498-507, 2014.

Kiontke, A., Oliveira-Birkmeier, A., Opitz, A., and Birkemeyer, C.: Electrospray Ionization Efficiency Is Dependent on Different Molecular Descriptors with Respect to Solvent $\mathrm{pH}$ and Instrumental Configuration, PLOS ONE, 11, e0167502, https://doi.org/10.1371/journal.pone.0167502, 2016.

Koop, T., Bookhold, J., Shiraiwa, M., and Pöschl, U.: Glass transition and phase state of organic compounds: dependency on molecular properties and implications for secondary organic aerosols in the atmosphere, Phys. Chem. Chem. Phys., 13, 19238-19255, 2011.

Krieger, U. K., Marcolli, C., and Reid, J. P.: Exploring the complexity of aerosol particle properties and processes using single particle techniques, Chem. Soc. Rev., 41, 6631-6662, 2012.
Kroll, J. H. and Seinfeld, J. H.: Chemistry of secondary organic aerosol: Formation and evolution of low-volatility organics in the atmosphere, Atmos. Environ., 42, 3593-3624, 2008.

Kroll, J. H., Ng, N. L., Murphy, S. M., Varutbangkul, V., Flagan, R. C., and Seinfeld, J. H.: Chamber studies of secondary organic aerosol growth by reactive uptake of simple carbonyl compounds, J. Geophys. Res.-Atmos., 110, https://doi.org/10.1029/2005JD006004, 2005.

Kroll, J. H., Donahue, N. M., Jimenez, J. L., Kessler, S. H., Canagaratna, M. R., Wilson, K. R., Altieri, K. E., Mazzoleni, L. R., Wozniak, A. S., Bluhm, H., Mysak, E. R., Smith, J. D., Kolb, C. E., and Worsnop, D. R.: Carbon oxidation state as a metric for describing the chemistry of atmospheric organic aerosol, Nat. Chem. 2011, 3, 133-139, 2011.

Kroll, J. H., Lim, C. Y., Kessler, S. H., and Wilson, K. R.: Heterogeneous Oxidation of Atmospheric Organic Aerosol: Kinetics of Changes to the Amount and Oxidation State of Particle-Phase Organic Carbon, J. Phys. Chem. A, 119, 10767-10783, 2015.

Lambe, A. T., Ahern, A. T., Williams, L. R., Slowik, J. G., Wong, J. P. S., Abbatt, J. P. D., Brune, W. H., Ng, N. L., Wright, J. P., Croasdale, D. R., Worsnop, D. R., Davidovits, P., and Onasch, T. B.: Characterization of aerosol photooxidation flow reactors: heterogeneous oxidation, secondary organic aerosol formation and cloud condensation nuclei activity measurements, Atmos. Meas. Tech., 4, 445-461, https://doi.org/10.5194/amt-4445-2011, 2011.

Laskin, A., Laskin, J., and Nizkorodov, S. A.: Mass spectrometric approaches for chemical characterisation of atmospheric aerosols: critical review of the most recent advances, Environ. Chem., 9, 163-189, 2012.

Li, Z., Smith, K. A., and Cappa, C. D.: Influence of relative humidity on the heterogeneous oxidation of secondary organic aerosol, Atmos. Chem. Phys., 18, 14585-14608, https://doi.org/10.5194/acp-18-14585-2018, 2018.

Liu, C. G. and Zeng, C. H.: Heterogeneous kinetics of methoxyphenols in the $\mathrm{OH}$-initiated reactions under different experimental conditions, Chemosphere, 209, 560-567, 2018.

Liu, J., Lin, P., Laskin, A., Laskin, J., Kathmann, S. M., Wise, M., Caylor, R., Imholt, F., Selimovic, V., and Shilling, J. E.: Optical properties and aging of light-absorbing secondary organic aerosol, Atmos. Chem. Phys., 16, 12815-12827, https://doi.org/10.5194/acp-16-12815-2016, 2016.

Liu, T., Huang, D. D., Li, Z., Liu, Q., Chan, M., and Chan, C. K.: Comparison of secondary organic aerosol formation from toluene on initially wet and dry ammonium sulfate particles at moderate relative humidity, Atmos. Chem. Phys., 18, 5677 5689, https://doi.org/10.5194/acp-18-5677-2018, 2018.

Liu, Y. J., Herdlinger-Blatt, I., McKinney, K. A., and Martin, S. T.: Production of methyl vinyl ketone and methacrolein via the hydroperoxyl pathway of isoprene oxidation, Atmos. Chem. Phys., 13, 5715-5730, https://doi.org/10.5194/acp-135715-2013, 2013.

Marsh, A., Rovelli, G., Song, Y.-C., Pereira, K. L., Willoughby, R. E., Bzdek, B. R., Hamilton, J. F., Orr-Ewing, A. J., Topping, D. O., and Reid, J. P.: Accurate representations of the physicochemical properties of atmospheric aerosols: when are laboratory measurements of value?, Faraday Discuss., 200, 639-661, 2017.

Mikhailov, E., Vlasenko, S., Martin, S. T., Koop, T., and Pöschl, U.: Amorphous and crystalline aerosol particles interacting with wa- 
ter vapor: conceptual framework and experimental evidence for restructuring, phase transitions and kinetic limitations, Atmos. Chem. Phys., 9, 9491-9522, https://doi.org/10.5194/acp-9-94912009, 2009.

Montgomery, J. F., Rogak, S. N., Green, S. I., You, Y., and Bertram, A. K.: Structural Change of Aerosol Particle Aggregates with Exposure to Elevated Relative Humidity, Environ. Sci. Technol., 49, 12054-12061, 2015.

Montoya-Aguilera, J., Hinks, M. L., Aiona, P. K., Wingen, L. M., Horne, J. R., Zhu, S., Dabdub, D., Laskin, A., Laskin, J., Lin, P., and Nizkorodov, S. A.: Reactive Uptake of Ammonia by Biogenic and Anthropogenic Organic Aerosols, in: Multiphase Environmental Chemistry in the Atmosphere, ACS Symposium Series, 1299, American Chemical Society, 2018.

Nakao, S., Tang, P., Tang, X., Clark, C. H., Qi, L., Seo, E., AsaAwuku, A., and Cocker, D.: Density and elemental ratios of secondary organic aerosol: Application of a density prediction method, Atmos. Environ., 68, 273-277, 2013

Nakayama, T., Matsumi, Y., Sato, K., Imamura, T., Yamazaki, A., and Uchiyama, A.: Laboratory studies on optical properties of secondary organic aerosols generated during the photooxidation of toluene and the ozonolysis of $\alpha$-pinene, J. Geophys. Res.Atmos., 115, https://doi.org/10.1029/2010JD014387, 2010.

Ng, N. L., Canagaratna, M. R., Jimenez, J. L., Chhabra, P. S., Seinfeld, J. H., and Worsnop, D. R.: Changes in organic aerosol composition with aging inferred from aerosol mass spectra, Atmos. Chem. Phys., 11, 6465-6474, https://doi.org/10.5194/acp11-6465-2011, 2011a.

Ng, N. L., Canagaratna, M. R., Jimenez, J. L., Chhabra, P. S., Seinfeld, J. H., and Worsnop, D. R.: Changes in organic aerosol composition with aging inferred from aerosol mass spectra, Atmos. Chem. Phys., 11, 6465-6474, https://doi.org/10.5194/acp11-6465-2011, 2011b.

Nizkorodov, S. A., Laskin, J., and Laskin, A.: Molecular chemistry of organic aerosols through the application of high resolution mass spectrometry, Phys. Chem. Chem. Phys., 13, 3612-3629, 2011.

Nozière, B., Kalberer, M., Claeys, M., Allan, J., D’Anna, B., Decesari, S., Finessi, E., Glasius, M., Grgić, I., Hamilton, J. F., Hoffmann, T., Iinuma, Y., Jaoui, M., Kahnt, A., Kampf, C. J., Kourtchev, I., Maenhaut, W., Marsden, N., Saarikoski, S., Schnelle-Kreis, J., Surratt, J. D., Szidat, S., Szmigielski, R., and Wisthaler, A.: The Molecular Identification of Organic Compounds in the Atmosphere: State of the Art and Challenges, Chem. Rev., 115, 3919-3983, 2015.

Oss, M., Kruve, A., Herodes, K., and Leito, I.: Electrospray Ionization Efficiency Scale of Organic Compounds, Anal. Chem., 82, 2865-2872, 2010.

Palm, B. B., Campuzano-Jost, P., Ortega, A. M., Day, D. A., Kaser, L., Jud, W., Karl, T., Hansel, A., Hunter, J. F., Cross, E. S., Kroll, J. H., Peng, Z., Brune, W. H., and Jimenez, J. L.: In situ secondary organic aerosol formation from ambient pine forest air using an oxidation flow reactor, Atmos. Chem. Phys., 16, $2943-$ 2970, https://doi.org/10.5194/acp-16-2943-2016, 2016.

Pankow, J. F.: An absorption model of gas/particle partitioning of organic compounds in the atmosphere, Atmos. Environ., 28, 185-188, 1994a.
Pankow, J. F.: An absorption model of the gas/aerosol partitioning involved in the formation of secondary organic aerosol, Atmos. Environ., 28, 189-193, 1994b.

Papapostolou, V., Lawrence, J. E., Diaz, E. A., Wolfson, J. M., Ferguson, S. T., Long, M. S., Godleski, J. J., and Koutrakis, P.: Laboratory evaluation of a prototype photochemical chamber designed to investigate the health effects of fresh and aged vehicular exhaust emissions, Inhal. Toxicol., 23, 495-505, 2011.

Parshintsev, J., Ruiz-Jimenez, J., Petäjä, T., Hartonen, K., Kulmala, M., and Riekkola, M.-L.: Comparison of quartz and Teflon filters for simultaneous collection of size-separated ultrafine aerosol particles and gas-phase zero samples, Anal. Bioanal. Chem., 400, 3527-3535, 2011.

Peng, Z., Day, D. A., Ortega, A. M., Palm, B. B., Hu, W., Stark, H., Li, R., Tsigaridis, K., Brune, W. H., and Jimenez, J. L.: Non-OH chemistry in oxidation flow reactors for the study of atmospheric chemistry systematically examined by modeling, Atmos. Chem. Phys., 16, 4283-4305, https://doi.org/10.5194/acp16-4283-2016, 2016.

Perraud, V., Bruns, E. A., Ezell, M. J., Johnson, S. N., Yu, Y., Alexander, M. L., Zelenyuk, A., Imre, D., Chang, W. L., Dabdub, D., Pankow, J. F., and Finlayson-Pitts, B. J.: Nonequilibrium atmospheric secondary organic aerosol formation and growth, $\mathrm{P}$. Natl. Acad. Sci. USA, 109, 2836-2841, 2012.

Pereira, K. L., Rovelli, G., Song, Y. C., Mayhew, A. W., Reid, J. P., and Hamilton, J. F.: A New Aerosol Flow Reactor to Study Secondary Organic Aerosol, https://doi.org/10.15124/282966e4c169-4235-94b2-07a4b936f5cd, 2019.

Pratt, K. A. and Prather, K. A.: Mass spectrometry of atmospheric aerosols - Recent developments and applications. Part I: Off-line mass spectrometry techniques, Mass Spectrom. Rev., 31, 1-16, 2012.

Reid, J. P., Bertram, A. K., Topping, D. O., Laskin, A., Martin, S. T., Petters, M. D., Pope, F. D., and Rovelli, G.: The viscosity of atmospherically relevant organic particles, Nat. Commun., 9, 956, https://doi.org/10.1038/s41467-018-03027-z, 2018.

Reinhardt, A., Emmenegger, C., Gerrits, B., Panse, C., Dommen, J., Baltensperger, U., Zenobi, R., and Kalberer, M.: Ultrahigh mass resolution and accurate mass measurements as a tool to characterize oligomers in secondary organic aerosols, Anal. Chem., 79, 4074-4082, 2007.

Riva, M., Budisulistiorini, S. H., Zhang, Z., Gold, A., Thornton, J. A., Turpin, B. J., and Surratt, J. D.: Multiphase reactivity of gaseous hydroperoxide oligomers produced from isoprene ozonolysis in the presence of acidified aerosols, Atmos. Environ., 152, 314-322, 2017.

Rohrer, F., Bohn, B., Brauers, T., Brüning, D., Johnen, F.-J., Wahner, A., and Kleffmann, J.: Characterisation of the photolytic HONO-source in the atmosphere simulation chamber SAPHIR, Atmos. Chem. Phys., 5, 2189-2201, https://doi.org/10.5194/acp5-2189-2005, 2005.

Roldin, P., Eriksson, A. C., Nordin, E. Z., Hermansson, E., Mogensen, D., Rusanen, A., Boy, M., Swietlicki, E., Svenningsson, B., Zelenyuk, A., and Pagels, J.: Modelling non-equilibrium secondary organic aerosol formation and evaporation with the aerosol dynamics, gas- and particle-phase chemistry kinetic multilayer model ADCHAM, Atmos. Chem. Phys., 14, 7953-7993, https://doi.org/10.5194/acp-14-7953-2014, 2014 
Rothfuss, N. E. and Petters, M. D.: Characterization of the temperature and humidity-dependent phase diagram of amorphous nanoscale organic aerosols, Phys. Chem. Chem. Phys., 19, 65326545, $2017 \mathrm{a}$.

Rothfuss, N. E. and Petters, M. D.: Influence of Functional Groups on the Viscosity of Organic Aerosol, Environ. Sci. Technol., 51, 271-279, 2017b.

Rovelli, G., Miles, R. E. H., Reid, J. P., and Clegg, S. L.: Accurate Measurements of Aerosol Hygroscopic Growth over a Wide Range in Relative Humidity, J. Phys. Chem. A, 120, 4376-4388, 2016.

Sakamaki, F., Hatakeyama, S., and Akimoto, H.: Formation of nitrous acid and nitric oxide in the heterogeneous dark reaction of nitrogen dioxide and water vapor in a smog chamber, Int. J. Chem. Kinet., 15, 1013-1029, 1983.

Seinfeld, J. H. and Pankow, J. F.: Organic atmospheric particulate material, Annu. Rev. Phys. Chem., 54, 121-140, 2003.

Shilling, J. E., Chen, Q., King, S. M., Rosenoern, T., Kroll, J. H., Worsnop, D. R., McKinney, K. A., and Martin, S. T.: Particle mass yield in secondary organic aerosol formed by the dark ozonolysis of $\alpha$-pinene, Atmos. Chem. Phys., 8, 2073-2088, https://doi.org/10.5194/acp-8-2073-2008, 2008.

Shilling, J. E., Chen, Q., King, S. M., Rosenoern, T., Kroll, J. H., Worsnop, D. R., DeCarlo, P. F., Aiken, A. C., Sueper, D., Jimenez, J. L., and Martin, S. T.: Loading-dependent elemental composition of $\alpha$-pinene SOA particles, Atmos. Chem. Phys., 9, 771-782, https://doi.org/10.5194/acp-9-771-2009, 2009.

Shiraiwa, M., Zuend, A., Bertram, A. K., and Seinfeld, J. H.: Gasparticle partitioning of atmospheric aerosols: interplay of physical state, non-ideal mixing and morphology, Phys. Chem. Chem. Phys., 15, 11441-11453, 2013.

Shrivastava, M., Cappa, C. D., Fan, J., Goldstein, A. H., Guenther, A. B., Jimenez, J. L., Kuang, C., Laskin, A., Martin, S. T., Ng, N. L., Petaja, T., Pierce, J. R., Rasch, P. J., Roldin, P., Seinfeld, J. H., Shilling, J., Smith, J. N., Thornton, J. A., Volkamer, R., Wang, J., Worsnop, D. R., Zaveri, R. A., Zelenyuk, A., and Zhang, Q.: Recent advances in understanding secondary organic aerosol: Implications for global climate forcing, Rev. Geophys., 55, 509559, 2017.

Simpson, A. J., Simpson, M. J., and Soong, R.: Nuclear Magnetic Resonance Spectroscopy and Its Key Role in Environmental Research, Environ. Sci. Technol., 46, 11488-11496, 2012.

Song, M., Liu, P. F., Hanna, S. J., Zaveri, R. A., Potter, K., You, Y., Martin, S. T., and Bertram, A. K.: Relative humiditydependent viscosity of secondary organic material from toluene photo-oxidation and possible implications for organic particulate matter over megacities, Atmos. Chem. Phys., 16, 8817-8830, https://doi.org/10.5194/acp-16-8817-2016, 2016.
Tasoglou, A. and Pandis, S. N.: Formation and chemical aging of secondary organic aerosol during the $\beta$ caryophyllene oxidation, Atmos. Chem. Phys., 15, 6035-6046, https://doi.org/10.5194/acp-15-6035-2015, 2015.

Tolocka, M. P., Jang, M., Ginter, J. M., Cox, F. J., Kamens, R. M., and Johnston, M. V.: Formation of Oligomers in Secondary Organic Aerosol, Environ. Sci. Technol., 38, 1428-1434, 2004.

Tuet, W. Y., Chen, Y., Xu, L., Fok, S., Gao, D., Weber, R. J., and Ng, N. L.: Chemical oxidative potential of secondary organic aerosol (SOA) generated from the photooxidation of biogenic and anthropogenic volatile organic compounds, Atmos. Chem. Phys. 17, 839-853, https://doi.org/10.5194/acp-17-839-2017, 2017.

Vaden, T. D., Imre, D., Beránek, J., Shrivastava, M., and Zelenyuk, A.: Evaporation kinetics and phase of laboratory and ambient secondary organic aerosol, P. Natl. Acad. Sci. USA, 108, 21902195, 2011.

Witkowski, B., Al-sharafi, M., and Gierczak, T.: Kinetics of Limonene Secondary Organic Aerosol Oxidation in the Aqueous Phase, Environ. Sci. Technol., 52, 11583-11590, 2018.

Xie, M., Chen, X., Hays, M. D., Lewandowski, M., Offenberg, J., Kleindienst, T. E., and Holder, A. L.: Light Absorption of Secondary Organic Aerosol: Composition and Contribution of Nitroaromatic Compounds, Environ. Sci. Technol., 51, $11607-$ 11616, 2017.

Yli-Juuti, T., Pajunoja, A., Tikkanen, O.-P., Buchholz, A., Faiola, C., Väisänen, O., Hao, L., Kari, E., Peräkylä, O., Garmash, O., Shiraiwa, M., Ehn, M., Lehtinen, K., and Virtanen, A.: Factors controlling the evaporation of secondary organic aerosol from $\alpha$ pinene ozonolysis, Geophys. Res. Lett., 44, 2562-2570, 2017.

Zhang, Q., Jimenez, J. L., Canagaratna, M. R., Ulbrich, I. M., Ng, N. L., Worsnop, D. R., and Sun, Y.: Understanding atmospheric organic aerosols via factor analysis of aerosol mass spectrometry: a review, Anal. Bioanal. Chem., 401, 3045-3067, 2011.

Zhang, X., Ortega, J., Huang, Y., Shertz, S., Tyndall, G. S., and Orlando, J. J.: A steady-state continuous flow chamber for the study of daytime and nighttime chemistry under atmospherically relevant NO levels, Atmos. Meas. Tech., 11, 2537-2551, https://doi.org/10.5194/amt-11-2537-2018, 2018.

Zhao, D. F., Kaminski, M., Schlag, P., Fuchs, H., Acir, I.-H., Bohn, B., Häseler, R., Kiendler-Scharr, A., Rohrer, F., Tillmann, R., Wang, M. J., Wegener, R., Wildt, J., Wahner, A., and Mentel, Th. F.: Secondary organic aerosol formation from hydroxyl radical oxidation and ozonolysis of monoterpenes, Atmos. Chem. Phys., 15, 991-1012, https://doi.org/10.5194/acp-15-991-2015, 2015.

Zobrist, B., Marcolli, C., Pedernera, D. A., and Koop, T.: Do atmospheric aerosols form glasses?, Atmos. Chem. Phys., 8, 52215244, https://doi.org/10.5194/acp-8-5221-2008, 2008 